\title{
Evaluation and Management of Bacterial and Fungal Infections Occurring in Patients with a Hematological Malignancy: A 2011 Update
}

\author{
James C. Wade
}

Keywords

Bacteria $\bullet$ Fungus $\bullet$ Infection $\bullet$ Cultures $\bullet$ Neutropenia $\bullet$ Immunosuppression

\section{Introduction}

Patients with a hematological malignancy are a heterogeneous patient population who are afflicted with diseases that range from rapidly fatal acute leukemia to indolent lymphoma or chronic leukemia. Treatment options for these patients range from observation to hematopoietic stem cell transplantation (HSCT), but all patients are more susceptible to infection. The problem of infection is dynamic with continued shifts in pathogenic organisms and microbial susceptibilities, new treatment regimens that further diminish immune function, and patients receiving treatment who are now olderand frailer. The classic patterns of immunodeficiency for patients with a hematological malignancy include: periods of profound neutropenia, increased iatrogenic risks (i.e., central vascular catheters), and cellular immune suppression that affects HSCT recipients, patients with lymphoid malignancies, and those receiving treatment with corticosteroids or agents like alemtuzumab [1-4]. Recent advances in antimicrobial drug development, new technology, clinical trial results, and further clinical experience have enhanced the database on which to make infection prophylaxis and treatment decisions. However, the practicing clinician must remember that the majority of basic infection management principles for patients who are neutropenic remain unchanged.

J.C. Wade, M.D., M.P.H. (ه)

Medical College of Wisconsin, 730 N. Plankinton Avenue, \#8D,

Milwaukee, WI 53203, USA

e-mail:wademdjc@gmail.com
This chapter will focus primarily on the most important bacterial and fungal infections that occur during periods of neutropenia, and will review and update management and evaluation approaches by addressing the following questions.

1. Recommended prophylaxis and prevention approaches for bacterial and fungal infections.

2. The importance of patient-risk stratification at the time of presentation with fever and neutropenia.

3. Initial infections: recommended treatment and management of presumed or documented bacterial infections.

4. Second or subsequent infections: recommended treatment and management of presumed or documented fungal infections.

\section{Fever and Neutropenia}

Standard evaluation and management principles for patients with fever and neutropenia are applicable to patients with a hematological malignancy, but risk stratification beyond the patient's underlying disease is now a recommended starting point for patients who are neutropenic and develop fever [5-8]. Neutropenia is primarily a consequence of the patients' underlying disease or treatment, although infection (e.g., cytomegalovirus [CMV], human herpes virus [HHV]-6, HHV-8, parvovirus B19), medication toxicity (e.g., ganciclovir, trimethoprim/sulfamethoxazole, linezolid), or graft rejection following HSCT are also important etiologies. Patients with neutropenia are immune compromised because of the absence of circulating neutrophils, plus the enhanced ability of the patient's endogenous colonizing flora to invade disrupted mucosal and skin barriers and cause infection [1, 2, $9,10]$. Infection risks are further increased when periods of neutropenia are prolonged because of delayed posttreatment 
Table 52.1 Pathogens causing infection syndromes during the neutropenic period

\begin{tabular}{lll}
\hline $\begin{array}{l}\text { Syndrome } \\
\text { First fever }\end{array}$ & $\begin{array}{l}\text { Relative } \\
\text { frequency }\end{array}$ & $\begin{array}{l}\text { Relative life- } \\
\text { threatening potential }\end{array}$ \\
$\quad \begin{array}{l}\text { Staphylococci } \\
\text { Viridans streptococci }\end{array}$ & $3+$ & $1+$ \\
$\quad 1+$ & $2+$ \\
Gram-negative bacilli & $1+$ & $3+$ \\
$\quad$ Respiratory virus & $1+$ & $1-3+$ \\
Subsequent infection & & \\
$\quad$ Antibiotic-resistant bacteria & $2+$ & \\
$\quad$ Gram-positive cocci & & $1+$ \\
$\quad$ Gram-negative bacilli & & $2-3+$ \\
Fungi & $2-3+$ & $3-4+$ \\
Respiratory virus & $1+$ & $1-3+$ \\
\hline
\end{tabular}

${ }^{a}$ Frequency and life-threatening potential increase from 1 to 4

marrow recovery, inadequate antitumor responses, or a relapse of their disease $[1,2]$. The primary sites of infection are limited and include the alimentary tract (i.e., mouth, pharynx, esophagus, large and small bowel, and rectum), sinuses, lungs, and skin. Febrile episodes that occur during periods of neutropenia should be considered infection, but depending on the clinical study more than $40-80 \%$ of such febrile episodes will not have an infecting pathogen identified $[1,2,11-13]$.

Bacterial pathogens are responsible for more than $90 \%$ of the "first" neutropenia-associated infections, but there has been substantial evolution in the spectrum of bacterial bloodstream isolates recovered from these patients over the past 30 years [14, 15]. Herpes simplex virus, cytomegalovirus, and the respiratory viruses (e.g., influenza A and B, parainfluenza, and respiratory syncytial virus [RSV]) may also be important initial pathogens or co-pathogens (Table 52.1). Antibiotic-resistant bacteria, yeast, and molds are less frequent "initial pathogens," but are the primary cause of the "second or subsequent" infections $[12,16]$.

Initial bacterial pathogens are frequently gram-positive cocci, and despite a decreased virulence of these pathogens, there is still significant attributable mortality with such infections [2, 11-13, 16-23]. Attributable mortality with coagulase-negative staphylococcal bloodstream infections has been reported to be $13.6 \%$ (95\% CI 4.2-22.9\%) and increases to $37.1 \%$ (95\% CI 10-64\%) for bloodstream infections (BSI) caused by vancomycin-resistant enterococci (VRE) [24-26]. Colonization with VRE is a prerequisite for infection and increases the patient's risk of developing a VRE bloodstream infection, and death following allogeneic transplantation [27]. The incidence of BSI with viridans streptococci for some oncology centers has been significant, and $10 \%$ of such viridans streptococcal infections will be associated with a "toxic-shock"-like syndrome that can be rapidly fatal despite appropriate antibiotics [20-22].
Table 52.2 Bacterial bloodstream isolates: MCW 2009

\begin{tabular}{lr}
\hline Single organism bacteremias & \\
\hline Total & 187 \\
Coagulase-negative staphylococci & 103 \\
Enterococci & 19 \\
VRE & 8 \\
Streptococcus spp. & 18 \\
Staphylococcus aureus & 9 \\
MRSA & 2 \\
Gram-negative bacilli & 26 \\
Pseudomonas aeruginosa & 2 \\
Atypical mycobacteria & 5 \\
Other & 7 \\
\hline MRSA methicillin-resistant & S. aureus; VRE vancomycin-resistant
\end{tabular}
enterococci

Table 52.3 Antibiotic susceptibility of bloodstream and tissue invasive gram-positive bacterial isolates: MCW 2009

\begin{tabular}{lllll}
\hline & \multicolumn{4}{l}{ Percent sensitive } \\
\cline { 2 - 5 } Organism & Cefepime & Cipro & Nafcillin & Vanco \\
\hline $\begin{array}{l}\text { Coagulase-negative } \\
\text { Staphylococcus }\end{array}$ & 31 & 24 & 28 & 100 \\
\hline Staphylococcus aureus & 75 & 80 & 85 & 100 \\
\hline Streptococcus sp. & 64 & 18 & 80 & 100 \\
\hline & Ampicillin & & Vancomycin & \\
\hline Enterococcus faecalis & 96 & & 100 & \\
Enterococcus faecium & 23 & & 48 & \\
\hline
\end{tabular}

Cipro Ciprofloxacin

Vanco Vancomycin

Gram-negative bacilli are still the most virulent bacterial pathogens for patients during periods of neutropenia [28]. The most common gram-negative bacilli remain Escherichia coli, Klebsiella spp., and Pseudomonas aeruginosa, but the increased use of broad-spectrum cephalosporins and carbapenem antibiotics has increased the isolation of beta-lactamresistant Enterobacter spp., Acinetobacter spp., and Stenotrophomonas maltophilia [29-32].

Resistance to multiple antibiotics poses a significant problem in planning empiric treatment, and it is critical to understand your institution's specific antibiotic susceptibility patterns. Antibiotic resistance remains most frequent among the gram-positive pathogens, specifically coagulase-negative staphylococci. Transplant recipients and patients with hematological malignancies at the Medical College of Wisconsin in the calendar year 2009 experienced 187 BSI, a rate of 0.289 bloodstream infections/100 patient-days (Table 52.2). Seventy-two percent of these infections occurred during periods of neutropenia, and more than half were caused by coagulase-negative staphylococci. The antibiotic resistance patterns for gram-positive cocci continue to show increasing levels of resistance to beta-lactam and fluoroquinolone antibiotics (Table 52.3). 
Pathogens responsible for the "second or subsequent infections" include antibiotic-resistant bacteria and fungi. Wingard et al. reported that $S$. epidermidis (coagulase-negative staphylococci) were responsible for up to $50 \%$ of these "second or subsequent infections" [16]. The incidence of coagulase-negative staphylococcus infections at this institution was likely due to the frequent use of fluoroquinolone agents as part of the initial empiric antibiotic regimen. Antibiotic-resistant gram-negative bacilli composed an additional $10 \%$, and the remaining pathogens were fungal. Subsequent infections with the exception of coagulase-negative staphylococci are difficult to diagnose, more resistant to treatment, and associated with the highest rates of morbidity and mortality [33-37].

\section{Evaluation and Management of Neutropenia-Associated Infections}

Effective care for patients with a hematological malignancy must begin with reliance on center-wide infection control programs, infection prevention techniques, and empiric and/ or preemptive therapy. There are several recently updated clinical practice guidelines that outline approaches for the prevention and treatment of infection in patients with neutropenia. The recommendations developed by the Infectious Disease Society of America (IDSA), American Society of Blood and Marrow Transplantation (ASBMT), and National Cancer Comprehensive Network (NCCN) are highly concordant and compose three comprehensive clinical guidelines [11-13]. It remains important for oncology centers to customize their practices based on their own patient population, their most frequently utilized cytotoxic regimens, and their local infection and antimicrobial susceptibility patterns.

\section{Infection Control}

The single-most powerful infection prevention measure for a patient with neutropenia remains frequent hand washing performed by the healthcare staff, the patient, and the patient's family. Hand washing, while effective, continues to be difficult to fully implement, and the maintenance of a high level of compliance remains a significant challenge [38]. Hand soap that contains chlorhexidine is recommended, and adds residual antimicrobial effect to the mechanical cleansing that occurs with the physical washing. Antimicrobial hand rubs can be used if soap, water, and sinks are not easily accessible. Alcohol-containing waterless products appear to be well tolerated and effective, but antimicrobial resistance among $C$. difficile has been reported [39]. Gloves when worn should be put on after entering a patient's room and the hand washing is complete. Gloves should never be used for more than one patient contact. Keeping staff and patient visitors who have respiratory symptoms (e.g., uncontrolled cough and respiratory secretions, conjunctivitis, systemic symptoms) from contact with high-risk patients may decrease the risk of patients acquiring a serious respiratory viral infection. One must remember in constructing isolation approaches that the modes of transmission of respiratory virus infections are both respiratory and direct patient contact. Annual vaccination of healthcare workers against viral influenza is important and strongly recommended.

Patients who become neutropenic are no longer routinely cared for in total sterile environments (LAF [laminar air flow] units), but HEPA filtered air with 8-16 air exchanges per hour, and single patient rooms are recommended. Outpatient clinics, waiting areas, and day-hospital facilities should also be well ventilated with air that has been cleansed by high-efficiency air (HEPA) filtration and constantly exchanged. Barrier isolation remains important for patients known to be colonized or infected with a pathogen that is multiply antibiotic-resistant, or has an increased propensity for nosocomial transmission (i.e., VRE, Clostridium difficile, respiratory viruses) [40]. Standardized hand hygiene, maximal sterile barrier precautions, cutaneous antisepsis with chlorhexidine before catheter insertion, antimicrobial catheters, and catheter placement performed exclusively by expert healthcare providers compose a "clinical care bundle" that significantly decreases catheter-related BSI [41]. Finally, a healthcare team that understands oncology treatment procedures and the importance of minimizing the nosocomial transmission of potential pathogens should deliver the care provided to patients with neutropenia.

\section{Prophylaxis: Bacterial Pathogens}

The concept of antibiotic prophylaxis has been tested since the 1980s. Most of these studies have demonstrated reductions in the incidence of febrile episodes and the incidence of documented gram-negative bacterial infections [42-44]. The strongest evidence for the efficacy of this approach has occurred when fluoroquinolone antibacterial prophylaxis was tested [45-47]. Despite this body of evidence, previous clinical guidelines have not recommended the use of antibacterial prophylaxis [48, 49]. Justification for these previous recommendations was based on these trials failing to show patient survival advantage, concerns about drugassociated adverse effects, cost, and the potential promotion of antibiotic-resistant bacteria and fungal overgrowth [50-55].

More recent clinical guidelines developed by the IDSA, ASBMT, and NCCN have modified their recommendations and now support the use of antibacterial chemoprophylaxis for patients who are anticipated to experience prolonged and profound (ANC $<100$ cells/ml for greater than 7 days) 
neutropenia [11-13]. Support for the change in recommendations is embodied in a published meta-analysis of placebo- or no treatment-controlled trials of fluoroquinolone prophylaxis that demonstrated a relative risk reduction of $48 \%$ and $62 \%$ in all-cause mortality and infection-related mortality, respectively, for fluoroquinolone recipients (RR 0.32, $95 \% \mathrm{CI}$ 0.13-0.82) [47, 56-60]. Antibacterial prophylaxis with levofloxacin as well as ciprofloxacin appears beneficial. Bucaneve et al. reported a significant reduction in the episodes of fever and documented infections when levofloxacin was used [56].

Allogeneic HSCT recipients and patients undergoing induction therapy for acute leukemia are patient groups that are consistently included in this "high-risk" group because of their anticipated neutropenia. Autologous HSCT recipients may also experience approximately 7 days of neutropenia, but the period of profound neutropenia $(<100 / \mu \mathrm{l})$ is often less, and consequently these patients maybe at lower risk for serious bacterial infections. The potential for bacterial resistance to fluoroquinolone-based chemoprophylaxis remains a substantial concern [59-65], and individual cancer centers have reported rising rates of resistance with the use of fluoroquinolones [58, 59, 61, 65]. High utilization of fluoroquinolones in oncology patients has been linked to increases in infections due to fluoroquinolone-resistant grampositive cocci, and $E$. coli and $C$. difficile enterocolitis, but recent meta-analyses could not confirm this later association [47, 58, 61, 66, 67]. In two centers, discontinuing routine fluoroquinolone prophylaxis for patients with hematological malignancy led to the prompt reduction in bacterial resistance rates and these changes had no significant impact on infection-related morbidity [61, 63].

Some experts have advocated adding a gram-positive agent to fluoroquinolone prophylaxis because staphylococci and viridans-group streptococci are frequently recovered $[45,46,68]$. Combinations of a fluoroquinolone plus antibiotics including penicillins, rifampin, or macrolides have been tested. Some reduction in the incidence of infections due to staphylococci and streptococci has been reported, but the incidence of neutropenic fever and infection-related mortality was not decreased $[45,46]$. These combinations are associated with increased rates of gastrointestinal toxicity, and persistent breakthrough infections with resistant grampositive pathogens have resulted in diminished enthusiasm for this approach $[45,46]$.

The question of when to initiate and discontinue antibacterial chemoprophylaxis has not been systematically studied. Most clinicians begin prophylaxis treatment on the first day of cytotoxic therapy, or the day following administration of the last dose of chemotherapy. Antibiotic prophylaxis is usually continued until neutropenia resolves, or until the patient develops fever and empiric antibiotics are initiated [11-13].

\section{Prophylaxis: Fungal Pathogens}

Fungal infections remain the major cause of infection-associated mortality and morbidity among patients with a hematological malignancy or HSCT recipients. Oncology centers continue to report an incidence of fungal infection that ranges from 5 to $20 \%$, but pathogenic fungal species have changed in the past decade with the increased use of antifungal antibiotics [37, 69-72]

Candida colonization is detected in up to $80 \%$ of patients with hematological malignancy, and will persist throughout treatment unless patients receive azole suppression [37]. The true incidence or risk of colonization with Aspergillus among patients receiving intensive therapy is less clear. Wald et al. in their study of 2,496 consecutive HSCT patients reported that only $2 \%$ of patients became colonized with Aspergillus after transplant, and only $21 \%$ of patients who developed invasive aspergillosis had colonization detected prior to infection [33]. However, when Aspergillus colonization was identified, it was highly associated with the development of invasive infection ( $60 \%$ positive predictive value), and this risk increased further ( $94 \%$ positive predictive value) when HSCT patients were neutropenic [33].

Clearly, some cases of fungal infection originate from environmental exposure, and this led in the past to patient management within sterile environments that included HEPA air filtration. Unfortunately, these approaches provided benefit only during the periods when patients were restricted to these clean environments. The use of masks by patients or healthcare workers has not consistently influenced the incidence of fungal infections. This lack of efficacy may in part be due to poor patient tolerance, or the inability of the masks to be a truly effective barrier against fungal spores.

\section{Primary Prophylaxis of Invasive Fungal Infections Candida}

Fluconazole prophylaxis is highly effective in reducing Candida albicans infections in patients who are neutropenic [72-80]. Fluconazole is well tolerated, and available in both oral and IV formulations. Fluconazole usage has changed the epidemiology of candidemia with a dramatic decrease in infections due to $C$. albicans, but a progressive increase in Candida species (C. glabrata and C. krusei) that are more resistant to fluconazole $[37,81]$. The threshold incidence of candida infection where fluconazole prophylaxis appears efficacious is in the range of 6-10\% [76-78]. Candida infection rates at this level are consequently seen among patients with hematological malignancy who experience prolonged neutropenia and receive intensive chemotherapy that induces severe oral and GI mucositis. However, invasive candidiasis among lower-risk patient populations is rare, and likely does not merit routine fluconazole prophylaxis [11-13, 72]. 
The efficacy of fluconazole prophylaxis for allogeneic HSCT recipients has been demonstrated by many trials, but report by Slavin and coworkers noted not only a decrease in the incidence of $C$. albicans infections, but also an improvement in overall patient survival [11-13, 75]. Marr et al. performed a second analysis of this later study cohort, and after more than 8 years posttreatment, survival was still significantly better (68/152 vs. 41/148, respectively), and the incidence of invasive candidiasis and death due to candida infections was still lower for fluconazole recipients [82]. This clinical benefit of fluconazole was also associated with a decrease in the incidence of Grade 3-4 gut GVHD [82].

Candida prophylaxis with echinocandins (micafungin, caspofungin, anulidulan) is also efficacious and well tolerated. These agents have the additional potential benefit of decreasing the incidence of invasive aspergillosis among "high-risk" patients $[79,83]$. The high cost of these agents and the need for parenteral administration have been limitations to the more general use of these agents. Yet, echinocandins or IV fluconazole can be very useful in patients with mucositis that precludes compliance with oral medications.

\section{Aspergillus}

The need for Aspergillus prophylaxis among neutropenic high-risk patients varies according to the patient's disease and chemotherapy regimen (i.e., induction for acute leukemia or myelodysplastic syndrome, preengraftment allogeneic HSCT). Prophylaxis appears to be beneficial when the baseline rate of invasive aspergillus infection is at least $6 \%$ [84-87].

The historical standard for antifungal prophylaxis for allogeneic transplant recipients has been fluconazole, but this agent does not provide anti-mold activity [11-13, 74, 75]. Oral itraconazole has activity against Aspergillus and a single meta-analysis demonstrated that there was a protective effect with the oral solution of itraconazole at doses of $200 \mathrm{mg}$ twice a day [86-88]. However, itraconazole is not routinely recommended because its prophylactic utility is hampered by the lack of robust clinical trial data, poor patient tolerance, and inconsistent oral bioavailability.

Posacoazole, a broad-spectrum antifungal agent, is active against aspergillus, but available in only an oral formulation, and its absorption is highly dependent upon the concomitant administration of a high fat meal. The drug bioavailability and potential drug interactions can make this therapy more difficult to administer $[89,90]$. However, posaconazole prophylaxis has been shown to be superior to fluconazole or itraconazole for patients undergoing acute leukemia induction or intensive treatment for advanced myelodysplastic syndrome [85].

Voriconazole, a triazole antifungal agent, has become widely utilized for antifungal prevention for patients at high-risk to develop invasive aspergillus infections. Voriconazole is available in both oral and IV formulations, and this clearly enhances the ease of utilization for patients who otherwise do not require hospitalization. Oral bioavailability of voriconazole or the appropriate dosage of voriconazole to achieve maximum clinical benefit is controversial, and thus serum voriconazole drug level monitoring is now being recommended to aid in clinical decision-making [91, 92].

Prophylaxis for aspergillosis may be beneficial for patients with acute leukemia who are expected to experience induction therapy-related prolonged neutropenia [11-13]. This antifungal prophylactic benefit has not been established for postremission consolidation therapy for acute leukemia, and thus is not routinely recommended. Posaconazole, when compared as antifungal prophylaxis to itraconazole or fluconazole among adult and adolescent patients ( $>13$ years of age) receiving induction chemotherapy for AML or intensive treatment for advanced MDS, was associated with more serious adverse events, but significantly decreased aspergillus infections and improved patient survival [85]. The prophylactic benefit of voriconazole for high-risk patients with hematological malignancies has been inferred from studies of voriconazole in patients undergoing allogeneic transplantation, and only one randomized study in patients with AML or MDS has been performed [93].

For allogeneic HSCT recipients, antifungal prophylaxis is now routinely prescribed for the first 75-120 days after transplant, or until patients with GVHD can have their immunosuppressant therapy discontinued [11-13, 72, 94]. The justification for this prolonged prophylaxis is based on the understanding that there are three distinct periods of risk for invasive mold infections post allogeneic transplant [95]. The first period is during the preengraftment neutropenic phase; the second is during the postengraftment period when patients are at highest risk to develop acute and or chronic GVHD that requires immunosuppressive treatment, and the third occurs late after transplant among patients with delayed immune reconstitution and persistent chronic GVHD. Fluconazole while an effective prophylactic antifungal agent for allogeneic HSCT recipients lacks anti-mold coverage and thus its prophylactic efficacy is restricted to preventing invasive candida infections [74, 75, 82]. However, allogeneic HSCT patients are also at risk for invasive molds, and thus it stands to reason that antifungal agents with activity against molds would provide enhanced prophylaxis, and potentially improve patient outcomes and survival.

A prospective, randomized double-blind trial has recently been reported by Wingard et al. that compared voriconazole to fluconazole as antifungal prophylaxis for allogeneic transplant recipients deemed to be at low-risk to develop an aspergillus infection [96]. Study participants received prophylaxis beginning pretransplant, and continued to until day 100 after 
transplant. Analysis of 600 study patients showed equivalent rates of invasive fungal infections, and similar fungal infection-free survival. There was a trend toward decreased Aspergillus infections among voriconazole recipients, but the incidence of medication-associated adverse effects or the need for empiric antifungal therapy was similar in both groups. The reason for this apparent diminished benefit from voriconazole prophylaxis is unclear, but the authors raised concern about the bioavailability of oral voriconazole. The authors also noted that despite the lack of apparent prophylactic efficacy of voriconazole for "low-risk" patients, these data may not be pertinent for patients at "high-risk" to develop invasive aspergillus infection, patients at high-risk to develop significant GVHD, or those patients undergoing transplantation for acute leukemia [96].

Posaconazole has also been compared to fluconazole in a large randomized, blinded multicenter trial as prophylaxis against invasive fungal infections among allogeneic transplant recipients who had developed severe GVHD [84]. The risks of developing invasive fungal infections and overall mortality were equivalent for both posaconazole and fluconazole recipients, but patients given posaconazole experienced a lower incidence of invasive aspergillus infections $(2.3 \%$ vs. $7.0 \%)$ and death caused by invasive fungal infections ( $1 \%$ vs. $4 \%$ ). Adverse events were similar for both study groups. Winston et al. have confirmed the safety, efficacy, and risk of breakthrough infections when posaconazole was used a prophylaxis for HSCT recipients [89]. Infection-associated mortality was reported to be low, $3.7 \%$, and aspergillus infections occurred among only 3 of 106 patients. However, 8 of 106 patients experienced breakthrough candida infections. The majority of these candida pathogens were posaconazole susceptible that raises concern about posaconazole oral bioavailability.

A comparative open label trial of voriconazole and itraconazole in allogeneic HSCT demonstrated a trend toward fewer fungal infections with voriconazole, but survival at days 100 and 180 after transplant was comparable [97]. There were more adverse gastrointestinal events for itraconazole recipients, and more adverse visual and hepatic events with voriconazole.

Thus the choice of antifungal prophylaxis is not straightforward and before clinicians make this decision they will need to know factors such as a prior history of an Aspergillus infection, the patient's risk for developing GVHD (an important predictor of invasive aspergillosis), patient's primary disease (AML), oral bioavailability of agents prescribed, and cost [11-13, 72, 94]. Additionally, since prolonged durations of neutropenia are associated with the development of invasive aspergillosis, many experts now recommend a moldactive agent for prophylaxis in patients with hematological malignancy who are anticipated to experience prolonged neutropenic periods of at least $10-14$ days [86]. While routine azole drug level monitoring during prophylaxis has not been routinely recommended, low serum levels of the oral moldactive azoles are now well described, and therefore drug level monitoring is becoming a commonly utilized aid for dosing select patients.

The duration of anti-mold prophylaxis in high-risk patients is uncertain. Prophylaxis stop dates for acute leukemia patients generally coincide with myeloid reconstitution. HSCT allograft transplant recipients should receive prophylaxis through at least 75-120 days after transplant, or until immunosuppressive therapy can be discontinued [11-13, 72, 94].

\section{Secondary Prophylaxis for Invasive Fungal Infection}

A prior history of disseminated candidiasis (e.g., chronic disseminated candidiasis) or invasive mold infection (e.g., aspergillosis) often raises concerns about the patient's suitability for further treatment. Many patients with a previous history of aspergillosis could potentially benefit from additional intensive standard chemotherapy, autologous transplantation, or allogeneic transplantation, but the risk of recurrent infection and death despite antifungal treatment has historically limited many patients' treatment options.

A retrospective review conducted at the Fred Hutchinson Cancer Research Center (FHCRC) reported patients with documented disseminated candidiasis before allogeneic transplantation [98]. These patients had no appreciable increased risk of recurrent candida BSI after transplantation. These authors concluded that a history of disseminated candidiasis once adequately treated was not a contraindication to allogeneic transplantation. The availability of antifungal antibiotics that are highly effective against invasive yeast now makes this management approach attractive and relatively easy to administer.

Management of patients with a previously documented aspergillus infection has been more difficult. Offner et al. reported that 16 of 48 patients who underwent HSCT with a pretransplant history of aspergillosis experienced a recurrence of aspergillosis posttransplant, and $88 \%$ of these recurrent infections were fatal [99]. Patients who received effective antifungal therapy as secondary prophylaxis but underwent an autologous rather than an allogeneic transplant had a lower frequency of recurrent infection and decreased infectionassociated mortality. The FHCRC experience with transplant recipients with a prior history of aspergillosis was equally discouraging [100]. Thirteen of forty-five patients, despite secondary prophylaxis with amphotericin B experienced recurrent Aspergillus infection, and all infections were fatal.

More encouraging data have recently been published by deFabritiis et al. and Cordonnier et al. using either caspofungin or voriconazole as secondary aspergillus prophylaxis $[101,102]$. deFaritiis noted that only 2 of 18 transplant recipients with a prior history of aspergillosis had progression or relapse of their invasive fungal infection when caspofungin 
was administered long-term posttransplant [101]. Similar encouraging results were reported by Cordonnier et al. [102]. In this trial the incidence of recurrent or progressive invasive fungal infection was only $6.3 \%$ when the patients received voriconazole as secondary prophylaxis [102].

Secondary prophylaxis with voriconazole, or caspofungin administered during periods of significant neutropenia (i.e., induction therapy for acute leukemia), or following HSCT should now be routinely used for all patients with a previous history of an invasive Aspergillus infection [2, 11, 72]. The previous recommendation to use amphotericin B as secondary prophylaxis is no longer appropriate because of its limited efficacy and therapy-associated toxicity. The use of newer agents as primary prophylaxis may make the clinical problem of invasive aspergillus infections less frequent, but when it does occur, patient posttransplant outcomes may be improved with the pre- and long-term posttransplant administration of new antifungal agents with activity against aspergillus.

\section{Evaluation and Treatment of Presumed and Documented Infection}

One must still assume that most episodes of fever and neutropenia are infectious in origin, and that these infections continue to have the potential to be rapidly fatal [1, 2, 11-13]. Despite several decades of study, the basic principles of treatment of fever and neutropenia have remained unchanged with a continued emphasis on empiric therapy at the first sign of infection or the development of fever in the setting of neutropenia [1, 2, 11, 13].

Signs and symptoms of inflammation and infection are often attenuated or absent in patients who are neutropenic. Infections of skin and soft tissue may lack indurations, erythema, warmth, or pustulation; a pulmonary infection may have no discernible infiltrate on chest radiograph; CSF pleocytosis might be absent in the setting of meningitis; and a urinary tract infection may demonstrate no pyuria. Fever is often the only sign of a serious infection, but it remains important to remember that infection for a small percentage of patients may exist in the absence of fever. In these clinical situations it is critical to begin treatment when these other clinical signs and symptoms of infection develop despite the absence of fever.

A detailed history remains important and should include identification of site-specific symptoms, information about antimicrobial prophylaxis, infection exposures, prior documented infections or pathogen colonization, and coexistence of noninfectious causes of fever. Underlying co-morbid conditions such as diabetes, chronic obstructive lung disease, and/ or recent surgeries should also be noted. The physical examination requires a careful search to detect subtle findings, especially at the sites that are commonly infected: skin (especially sites of previous procedures or catheters, such as catheter entry and exit sites or bone marrow aspiration sites), oropharynx (including periodontium), alimentary tract, lungs, and perineum.

Diagnostic tools include blood tests, microbiological cultures, and radiographic studies. Cultures should be obtained of the blood and all apparent clinical sites of infection. The crucial determinant in detecting a BSI is the total volume of blood cultured [103-105]. At least two sets of blood cultures should be drawn, where a "set" consists of $20 \mathrm{ml}$ of blood divided into both aerobic and anaerobic blood culture bottles. Retrospective studies have reported that two blood culture sets detect $80-90 \%$ of bloodstream pathogens, while three or more sets are required to achieve greater than $96 \%$ detection [104]. In the neutropenic cancer patient, collection of blood culture sets from all central venous catheter (CVC) lumens (if present) and peripheral vein has been recommended $[11,13,106]$. Yet, some experts question the importance of the additional peripheral vein blood culture, and believe that sets of blood cultures that only drawn from CVC comprise an adequate evaluation [13]. This latter recommendation which avoids culturing of peripheral blood remains controversial, and it does not provide the blood specimen necessary to help define the role of the CVC in the bloodstream infection [107]. However, it does eliminate the routine need for peripheral venipuncture, and it decreases patient discomfort and cost. Additional sets of blood cultures may be obtained on each of the next 2 days if fever persists after empiric antibiotics have been started. Blood cultures drawn beyond the initial febrile period should only be obtained based on changes in the patient's clinical status and not just persistent fever. Recrudescent fever after the initial fever has completely resolved in a different clinical entity, and often signals a new episode of infection that requires a clinical evaluation plus additional blood cultures.

Culture of the sites listed next should be guided by clinical signs and symptoms, and not routinely performed.

1. Stool: A stool specimen in a patient with diarrhea should be evaluated for the presence of $C$. difficile toxin. There is limited value for sending stool for bacterial pathogen cultures or for ova and parasite examinations in most patients treated in U.S. hospitals unless there has been recent travel to or residence in endemic areas.

2. Urine: Culture of urine samples is indicated if signs or symptoms of urinary tract infection exist, a urinary catheter is in place, or the urinalysis is abnormal.

3. CSF: Examination and culture of spinal fluid is indicated only if meningitis is suspected. Platelet transfusion should be given prior to lumbar puncture if thrombocytopenia is present.

4. Skin: Aspiration or biopsy of skin lesions suspected of being infected should be performed and submitted for histological testing, gram staining, and culture [108]. 
5. Respiratory specimens: Sputum samples are rarely helpful. Lower respiratory tract specimens obtained by bronchoalveolar lavage (BAL) are recommended for patients with an infiltrate of uncertain etiology that is detected on chest imaging. Nasal wash and/or BAL specimens are recommended to evaluate for symptoms of respiratory virus infections particularly during an outbreak or the winter months. These specimens should be tested for the presence of adenovirus, influenza A and B, respiratory syncytial virus, and parainfluenza.

Patients with respiratory signs and symptoms should have a chest radiograph performed to rule out pneumonia. Pneumonia during neutropenia can progress rapidly to respiratory compromise, and therefore should initially be managed in the hospital. The serial determination of the patient's resting oxygen saturation can also be helpful. CT scans of the head, sinuses, chest, abdomen, and pelvis should be performed as clinically indicated. Laboratory studies including complete blood cell counts and determination of the levels of serum creatinine and urea nitrogen are needed to plan empiric antibiotic therapy, and to monitor for the possible occurrence of drug toxicity. These tests should be done at least two times per week, and weekly monitoring of serum transaminase levels is advisable for patients with complicated courses or suspected liver injury.

\section{Risk Assessment}

The new evaluation tools for patients with fever and neutropenia have been the development and validation of objective schemes to assess the risk of infection-associated complications at the time that patients present with fever and neutropenia. These patients may experience a variety of clinical outcomes, and numerous studies have sought to stratify patients at presentation into those with high versus low-risk for complications of infection [109-117]. In the past, "highrisk patients" were those who had substantial co-morbidities, advanced age, and "in the experience of clinical experts," were expected to experience sustained and profound neutropenia. "High-risk" patients have also been frequently identified based on underlying cancer diagnosis (hematological malignancy vs. solid tumor), or the intensity of treatment (induction therapy for acute leukemia or HSCT vs. conventional cytotoxic chemotherapy). These classifications which were often most helpful in a retrospective manner were also frequently utilized to select the patients who in the future were likely to benefit from antimicrobial prophylaxis.

The Multinational Association for Supportive Care in Cancer (MASCC) developed and validated a risk assessment scheme and scoring method that groups patients with fever and neutropenia into low or high-risks of infection-associated complications and death [7]. The MASCC score has also been found to be a helpful means to determine which patients require prolonged hospitalization, and those that may be candidates for oral or once-daily IV antibiotic regimens and/or early discharge to complete the antibiotic course as outpatients [5-8, 115, 116].

The MASCC scoring system is a summation of weighted risk factors, including patient age, history, outpatient or inpatient status, acute clinical signs, the presence of medical comorbid conditions, and severity of fever and neutropenia as assessed by "burden of illness." "High-risk" patients are identified by a cumulative score of $<21$ points [7]. A fundamental difficulty with the MASCC system has been the subjective nature of one of its major criteria: the so-called burden of febrile neutropenia. This measure of how "sick" the patient appears to be on presentation can be confusing $[115,116]$. Despite this apparent deficiency, a large validation study classified 441 febrile neutropenic patients as "low-risk" and only $5 \%$ of these patients developed serious medical complications and 3 patients required readmission for fever or major complications.

MASCC assessment tool factors are relevant for patients with hematological malignancy, but these patients will frequently be scored as "high-risk" for the development of serious complications during fever and neutropenia [7]. "High-Risk Patients" are those with profound neutropenia (ANC $\leq 100$ cells $/ \mathrm{mm}^{3}$ ) who are anticipated to extend more than 7 days; and those patients who are already hospitalized when fever develops and/or the presence of co-morbid medical problems including:

1. Hemodynamic instability

2. Oral or GI mucositis that interferes with swallowing or causes severe diarrhea

3. Gastrointestinal symptoms, including abdominal pain, nausea and vomiting, or diarrhea

4. Neurological or mental-status changes of new onset

5. Intravascular catheter infection, especially catheter tunnel infection that requires immediate catheter removal

6. New pulmonary infiltrate or hypoxemia, or significant underlying chronic lung disease

7. Evidence of hepatic insufficiency (defined as aminotransferase values greater than $5 \times$ normal values) or renal insufficiency (defined as a creatinine clearance of less than $20 \mathrm{ml} / \mathrm{min}$ ).

Duration of neutropenia was not initially included as a criterion for risk in the MASCC assessment scheme, but this is clearly an important factor [118]. Patients in whom prolonged neutropenia is expected as a consequence of HSCT preparation or induction chemotherapy for AML are almost always judged to be "high-risk". Patients undergoing autologous HSCT or consolidation therapy for leukemia may also experience prolonged neutropenia, but because of the other factors included in the MASCC risk assessment scheme they maybe scored as "low-risk." Finally, a review of the MASCC 
criteria applied to a large population at one U.S. cancer centers found that the MASCC tool will consistently identify patients with minimal medical co-morbidity short durations of neutropenia ( $\leq 7$ days) and solid tumors receiving conventional outpatient chemotherapy as "low-risk" [114].

\section{General Considerations of Management}

The initial evaluation and management for patients with fever and neutropenia are well outlined in the published clinical guidelines of the IDSA, ASBMT, and NCCN [11-13]. In the latest version of these practice guidelines a neutrophil count of less than $500 / \mu \mathrm{l}$ defines neutropenia; a single temperature of greater than $38.0{ }^{\circ} \mathrm{C}$ describes fever requiring clinical intervention, and the goal of initial empiric antibiotic therapy remains the prevention of serious morbidity and mortality due to bacterial pathogens.

A large prospective observational study revealed that $23 \%$ of all febrile neutropenic episodes were associated with bacteremia [118]. Gram-positive, gram-negative, and polymicrobial bacteremias occurred at a frequency of $57 \%$, $34 \%$, and $9 \%$, respectively. Gram-negative bacteremias were associated with the highest mortality (18\%). Coverage of Pseudomonas aeruginosa has largely driven the recommended antibiotic choices for fever and neutropenia because of the high mortality rates associated with this pathogen. A recent study continues to demonstrate that delaying appropriate antibiotic therapy for $P$. aeruginosa bacteremia for 2 or more days is associated with a doubling of the 30-day mortality [119]. Thus $P$. aeruginosa coverage remains an essential component of the initial empiric antibiotic regimen for patients with neutropenia and fever in the current era $[11,13]$.

Despite decades of well-performed clinical trials, no single empiric regimen has emerged as clearly superior treatment of febrile patients with neutropenia [11, 13]. All effective empiric antibiotic regimens (combination or monotherapy) share the essential characteristics of bactericidal activity in the absence of neutrophils, anti-pseudomonal activity, and minimal toxicity. In recent years, antibioticresistant pathogens have become more common, and now pose a significant new challenge for neutropenic and other hospitalized patients [120-122]. Routine empiric coverage of all bacteria is not possible, and therefore the aim should be to provide empiric coverage for the most common and the most virulent pathogens. This may be accomplished with a variety of antibiotic regimens, but the ultimate selection of a particular empiric antibiotic regimen should continue to be based on the risk status of the patient (high vs. low-risk), localizing signs or symptoms of infection such as pneumonia, enteritis, or cellulitis, and the local institution and individual patient patterns of bacterial resistance and colonization.

\section{Initial Antibiotics for High-Risk Patients with Hematological Malignancies}

High-risk patients usually require inpatient management with IV broad-spectrum antibiotic therapy. Monotherapy with an anti-pseudomonal $\beta$-lactam agent such as cefepime, a carbapenem (imipenem-cilastatin or meropenem), or piperacillin-tazobactam are each as effective as multidrug combinations and are recommended as first-line therapy $[11,13]$. A recent meta-analysis reported that $\beta$-lactam monotherapy provided significant advantages with fewer adverse events, lower morbidity, while similar rates of survival when compared to $\beta$-lactam plus aminoglycoside combinations [123].

Many centers have found that ceftazidime has become a less reliable agent for empiric monotherapy of fever and neutropenia because of its decreasing activity against gram-negative organisms, and many gram-positive pathogens such as streptococci [124, 125]. Aminoglycoside monotherapy should not be used for either empiric coverage or pathogendirected therapy during neutropenia because of the rapid emergence of microbial resistance to this class of agents. Ciprofloxacin monotherapy is not an adequate treatment for febrile neutropenic patients because of its weak activity against gram-positive organisms, especially viridans streptococci $[126,127]$. The combination of vancomycin or clindamycin plus ciprofloxacin may be a suitable alternative for $\beta$-lactam-allergic patients [66]. Double $\beta$-lactam regimens are discouraged due to concerns about increased expense and toxicity, and the lack of consistent added clinical benefit [128, 129]. Cefepime remains an acceptable monotherapy for empiric coverage of febrile neutropenia. A meta-analysis by Yahav and colleagues previously reported an increased 30-day mortality with cefepime treatment (RR 1.41, $95 \%$ CI 1.08-1.84) [130]. This study raised doubt about the efficacy of the drug, and prompted the U.S. Food and Drug Administration (FDA) to undertake a second comprehensive meta-analysis, using an expanded dataset [http://www.fda. gov/Drugs/DrugSafety/PostmarketDrugSafety]. The FDA study found no statistically significant increase in 30-day mortality with cefepime (RR 1.20, $95 \%$ CI 0.82-1.76), and thus cefepime continues to be a reliable first-line agent for empiric antibiotic coverage for fever and neutropenia.

Antibiotic-resistant gram-negative bacterial species are now more common pathogens in febrile patients with neutropenia [28, 131, 132]. Among these resistant organisms, extended spectrum $\beta$-lactamase (ESBL) genes that confer a broad range of $\beta$-lactam antibiotic resistance, primarily among Klebsiella spp. and E. coli, are being detected [131]. Carbapenemase-producing organisms including Klebsiella spp. and Pseudomonas aeruginosa may also cause infections refractory to imipenem or meropenem [132]. Recognition of these resistant species requires careful interpretation of hospital and organism-specific antibiograms and pathogendirected therapy. 
Table 52.4 Indications for the empiric addition of gram-positive active antibiotics (e.g., vancomycin, linezolid, daptomycin)

- Hemodynamic instability, or other evidence of sepsis

- Positive blood culture for a gram-positive bacteria, pending identification and susceptibility testing

- Clinically documented serious catheter-related infection

- Skin or soft tissue infection at any site

- Clinically documented pneumonia

- Colonization with methicillin-resistant Staphylococcus aureus, penicillin-resistant Streptococcus pneumonia, or vancomycinresistant enterococci

- Severe mucositis if patient previously treated with fluoroquinolone antibacterial prophylaxis

Vancomycin is not recommended as a standard part of empiric antibiotic therapy for fever and neutropenia. Despite the predominance of gram-positive organisms as the cause of bacteremia during fever and neutropenia, randomized studies comparing empiric regimens with and without vancomycin have failed to show significant reductions in either the duration of fever or overall mortality [133, 134]. Coagulasenegative staphylococci, the most commonly identified cause of bacteremia in patients with neutropenia, are considered less virulent pathogens, and can usually be successfully treated once the pathogen is identified [133].

The primary reason to limit the use of empiric vancomycin is the emergence of vancomycin-resistant pathogens, and the development of colonization with VRE has been associated with the increased use of vancomycin although other antibiotics are also important [135-137]. Despite the risk of developing drug resistance, there are specific circumstances that warrant the empiric addition of vancomycin (or other antibiotics with enhanced gram-positive coverage, i.e., linezolid, daptomycin) to the initial antibiotic regimen (Table 52.4) [11, 13, 138]. If such empiric therapy is initiated, it should be reassessed and discontinued after 3-4 days of treatment if an antibiotic-resistant organism is not identified.

In view of the widespread presence of MRSA in both hospital and community settings, there may be for some centers an epidemiological rationale to employ vancomycin as a part of the empiric regimen $[139,140]$. Thus, neutropenic patients who are MRSA-colonized may benefit from the early empiric vancomycin.

Antibiotic-resistant viridans streptococci BSI in patients with neutropenia may result in shock and adult respiratory distress syndrome (ARDS) [141-143]. Gastrointestinal mucositis, ceftazidime use, and prophylaxis with fluoroquinolones have been noted to be important risk factors for the development of these serious infections during periods of neutropenia. Early vancomycin treatment has been reported to reduce mortality, but it is important to remember that monotherapy regimens including cefepime, carbapenems, and piperacillin/tazobactam provide excellent coverage of viridans streptococci and are considered adequate solo agents for febrile neutropenia in patients with oral mucositis, precluding the need for routine vancomycin.

Pneumococci and stomatococci with reduced susceptibility to $\beta$-lactam and fluoroquinolone drugs may also cause fulminant infection, but they currently represent a small minority of pathogens affecting patients who are neutropenic [144, 145].

Vancomycin-resistant enterococcal (VRE) bloodstream infections in the setting of fever and neutropenia are difficult to treat, and are independent risk factors for death for patients with acute leukemia and/or HSCT recipients [135, 137]. VRE colonization is an important risk factor for subsequent invasive disease, and individual patient patterns of bacterial colonization and resistance must be taken into account when choosing an initial empiric regimen for "high-risk" neutropenic patients $[11,13]$.

As with vancomycin, newer gram-positive agents such as linezolid, quinupristin-dalfopristin, tigecycline, televancin, or daptomycin have no proven role in routine empiric coverage $[11,13,146]$. Some hazards related to the use of these gram-positive agents include the emergence of linezolidresistant Enterococcus spp. and strains of coagulase-negative staphylococci, marrow suppression with linezolid and daptomycin, serum creatine kinase level elevation with daptomycin, and severe arthralgias with quinupristin-dalfopristin [147-150]. Consequently, these agents should be used only for targeted therapy of specific pathogens, or for empiric use in patients with hematological malignancy colonized with VRE who develop fever [11, 13, 149].

All patients with neutropenia and fever must be monitored closely for infection response, adverse effects, emergence of secondary infections, and the development of drug-resistant organisms. With empiric antibiotics, the median time to defervescence is frequently longer than 5 days $[151,152]$. Persistent fever alone, in an otherwise stable patient, is rarely an indication to alter the empiric antibiotic regimen. Rather specific antimicrobial additions or changes to the empiric regimen should be guided by clinical changes and or diagnostic culture results. Broader decisions about when and how to modify antimicrobial coverage during the course of neutropenia should be based on the patient's risk category (low or high), the source of fever in documented infections, and the clinical judgment about whether the patient is responding to the initial regimen. Once patients have stabilized and in vitro susceptibilities are known for isolated pathogens, antibiotics can often be consolidated to monotherapy with a $\beta$-lactam agent that provides adequate coverage for most uncomplicated infections during neutropenia.

The traditional approach to duration of antibiotic therapy for a fever of unidentified etiology has been to continue broad-spectrum antibiotics until the patient is afebrile, and 
the neutrophil count is $>500$ cells/ $\mu$ l with a consistent rising trend. This approach has proven safe and effective over the years, and continues to be based on the belief that while antibiotics are required to control an occult infection during neutropenia, full patient protection only occurs with the return of adequate circulating neutrophils.

\section{Patients with Documented Infection Sites or Bacterial Pathogens}

The duration of antibiotic therapy for documented infections must be based on being able to provide effective eradication of the identified infection [151]. Duration of treatment for documented infections should consider the following factors: (1) neutrophil recovery, (2) rapidity of response to the antimicrobial therapy, (3) the specific site of infection, and (4) the isolated pathogens. Most uncomplicated bacterial bloodstream and soft tissue infections require 10-14 days of appropriate antibiotic therapy, while bacterial sinusitis and pneumonia require 3-4 weeks of therapy to effectively control these infections [11, 13, 152-155]. More prolonged antimicrobial treatment is often required if the causative pathogen is $P$. aeruginosa or a mold, and antibiotics for these latter infections often must be extended beyond resolution of fever and neutropenia.

Pneumonia in patients with neutropenia should generally be treated as a healthcare-acquired infection according to the recent guidelines from the American Thoracic Society [156]. Patients with pneumonia who are neutropenic should be considered to be at high-risk for infections with multidrug-resistant pathogens, and initial broad-spectrum treatment with combinations of a $\beta$-lactam or carbapenem plus an aminoglycoside or antipseudomonal fluoroquinolone is recommended. The empiric addition of vancomycin, linezolid, or daptomycin is appropriate for severe cases of pneumonia as defined by hypoxia, extensive infiltrates, or suspicion of MRSA as the etiological pathogen. Initiation of inadequate or limited antibiotic regimens for healthcare-associated pneumonia is a major risk factor for excess mortality, prolonged hospital length of stay and must be avoided [151] When possible, patients with pneumonia should be evaluated with BAL and biopsy.

For gram-positive bloodstream isolates or for skin and soft tissue infections, the early addition of vancomycin (or linezolid or daptomycin) is recommended until susceptibility results are available for the isolated organism(s) [149]. Other specific sites of documented infection should be covered according to the potential or identified pathogens. Oral ulcerations or symptoms of esophagitis may represent herpes simplex or Candida esophagitis in high-risk patients, so empiric additions of acyclovir and/or fluconazole or other antifungal agents are appropriate. The onset of severe abdominal pain,
Table 52.5 Central venous catheter-associated infections

\begin{tabular}{ll}
\hline Infection & Treatment/action \\
\hline Entry site infection & Pathogen-specific therapy \\
& (consider empiric vancomycin \\
& treatment)
\end{tabular}

Tunnel infection

Catheter removal/culture

Pathogen-specific therapy

(consider empiric vancomycin treatment)

Bloodstream infection

Pathogens

Fungi (yeast or mold)

Therapy

Immediate catheter removal and

Nontuberculosis mycobacteria

Vancomycin-resistant enterococci

Corynebacterium jeikeium

Staphylococcus aureus

Bacillus sp.

Consider early catheter removal

Pseudomonas aeruginosa

Stenotrophomonas maltophilia

(+) Blood culture with any pathogen persisting $>48 \mathrm{~h}$, no other site of infection

Pathogen-specific therapy, consider catheter removal for persistent blood stream infection

typically in the right lower quadrant, suggests neutropenic enterocolitis (also referred to as "typhlitis"). A CT scan of the abdomen and pelvis should be obtained for additional evaluation [157, 158]. Since anaerobes and gram-negative organisms predominate in causing neutropenic enterocolitis, monotherapy with piperacillin-tazobactam or a carbapenem, or a combination of an anti-pseudomonal cephalosporin plus metronidazole, are appropriate antibiotic regimens. There is less evidence for routine additions of vancomycin or an antifungal agent, but should be considered if the patient is hemodynamically unstable $[11,13]$. These patients may benefit from surgical evaluation as a bowel resection maybe required for patients who develop uncontrolled sepsis, bleeding, or ischemic bowel.

Long-term indwelling CVC were initially developed for use in HSCT recipients, but are now the standard-of-care for almost all patients who receive intensive cancer treatment. Catheter-related infections are categorized as entry-site infections, tunnel infections, or catheter-related bloodstream infections (CRBSI) (Table 52.5). The delineation of an entrysite infection from a tunnel infection can be clinically challenging, but the occurrence of an apparent entry-site infection plus a BSI usually indicates that the catheter tunnel is infected. It is now believed that the majority of entry-site infections can be managed effectively with antimicrobial therapy alone, but tunnel infections require catheter removal coupled with modification of the empiric antibiotics based on culture and antibiotic susceptibility results.

CVC are a major source of BSI in the neutropenic patient population $[19,159,160]$. The hub/lumen of the tunneled 
catheter is believed to be the major site of colonization, and the source of the catheter-related bloodstream infections (CRBSI). CRBSI are most commonly caused by coagulasenegative staphylococci, $S$. aureus and Candida spp., and less common organisms including Bacillus spp., Corynebacterium $\mathrm{JK}$, enterococci (including VRE), rapidly growing mycobacteria, and non-fermentative gram-negative bacilli [159].

Determination of the true role of the CVC in a CRBSI is difficult unless there is evidence of tunnel or entry-site inflammation caused by the same organism. Most BSI that occur in patients with a hematological malignancy can be effectively treated without catheter removal. This clinical experience suggests that most of these BSI do not actually originate or involve the catheter [11, 13, 159]. However, immediate catheter removal is recommended for those patients with BSI caused by fungi, nontuberculosis mycobacterium ( $M$. fortuitum complex and $M$. chelonae/abscessus group), and VRE because of the consistent lack of infection response until this device is discontinued [11, 13, 159]. Persistent BSI are also more frequent if the catheter is not removed when the bloodstream pathogen is a Bacillus sp., C. jeikeium, S. aureus, $P$. aeruginosa, or Stenotrophomonas maltophilia [11, 13, 159]. Most other BSI can initially be treated with pathogen-specific antibiotics, but catheter removal should be considered when the BSI persists beyond $48 \mathrm{~h}$ and no other site of infection is identified. One additional caveat is that the CVC should be considered a potential site of infection for those bacteremias that recur shortly after completing a course of antibiotics [159].

There is inadequate data to support the recommendation that antibiotic administration be alternated through the different catheter lumens [160, 161]. One must believe that if the catheter is truly the source of infection then in most situations antibiotics will have a very low chance of sterilizing the CVC. Thus effective infection management for CRBSI would demand catheter removal.

Controversy continues around the clinical usefulness of attempting to confirm involvement of the catheter in BSI where other sites of infection are absent. The most useful diagnostic tool for attempting to diagnose a CRBSI is the differential time to positivity (DPT) of blood cultures drawn simultaneously through the catheter and peripheral vein [159, 162-165]. Quantitative blood cultures have also been recommended in the past, but they are not routinely recommended because of their cost and limited clinical utility [159]. The premise of the DPT test is that if the catheter is the source of the BSI then the concentration of organisms in the catheter will be higher than in the peripheral blood, and blood cultures drawn from the CVC will become positive more quickly. Studies suggest that a CVC blood culture that becomes positive at least 120 min earlier than a simultaneously drawn peripheral vein blood indicates the catheter to be the likely source of infection [165]. Once antibiotics have been started, DPT testing is likely less reliable.

The need for catheter removal is an important clinical consideration in the management of most CRBSIs, and forms the justification for attempting to define the role of the catheter in the BSI. The controversy that surrounds the need to define the role of the catheter in these infections is because decisions to remove the catheter are rarely made based on laboratory documentation of catheter involvement, but rather based on the specific organism(s) isolated, or the presence of a tunnel infection $[11,13,159]$.

In some patients catheter removal is not clinically feasible because of thrombocytopenia, enhanced hazards associated with reimplantation during neutropenia, the absence of other vascular access sites, or the presence of progressive or refractory cancer. In these complex cases where the catheter is to be retained, it is prudent to prolong the duration of IV antimicrobial therapy. Anecdotal data have suggested that antibiotic lock therapy might be useful in salvaging some of these infected CVC, but this strategy is not routinely recommended.

The duration of systemic antimicrobial therapy when a CRBSI is suspected depends on several factors including catheter removal or retention, response to antimicrobial therapy within the first 48-72 h (resolution of fever and bacteremia), and the development of other complications (deep tissue infection, septic thrombosis, or endocarditis) [11, 13, 159]. In general, for organisms other than coagulase-negative staphylococci, a 14-day course of systemic antimicrobial therapy is adequate in a patient with neutropenia assuming the patient responds to antimicrobial therapy within 48-72 h, and the CRBSI is not complicated by a deep tissue infection. However, a recent study was suggested that $S$. aureus CRBSI in cancer patients (including neutropenic patients) may benefit from durations of therapy that are longer than 2 weeks because of the increased risk of complications with shorter treatment courses [166]. CRBSI from any pathogen that is complicated by disseminated or deep infection requires at least 4-6 weeks of antimicrobial therapy [11, 13, 159].

\section{Site of Care for Patients with Fever and Neutropenia}

There is increasing acceptance that some "low-risk" patients with fever and neutropenia can be safely managed as outpatients, or with shortened hospital stays [11, 13, 166, 167]. The development of validated risk assessment model has been helpful in these clinical decisions, but in general, most models have excluded patients with acute leukemia undergoing induction therapy, or HSCT recipients from the "lowrisk" patient group [7]. 
Effective outpatient therapy requires the treating physician and cancer center to have implemented an infrastructure for patient care and monitoring that is available $24 \mathrm{~h} /$ day, 7 days a week. Healthcare providers who are trained to manage these complex patients should perform patient assessment and monitoring. Success of this approach will also depend on patient and family education, and the physician's willingness to recommend hospitalization if the patient's clinical condition changes or the patient and family request such care.

Outpatient antibiotic treatment may consist of broadspectrum intravenous antibiotics given at home, once-daily broad-spectrum antibiotics given at home or in the clinic, or a combination of oral agents. The present data suggest that if an oral regimen is considered then the combination of a fluoroquinolone (ciprofloxacin) and an agent with enhanced gram-positive activity (amoxicillin/potassium clavulanate [Augmentin] or clindamycin) is recommended [11, 13]. Levofloxacin is frequently utilized, but has not been carefully studied. The anti-pseudomonal activity of levofloxacin at a daily dose of $500 \mathrm{mg}$ is probably inadequate, and higher bactericidal drug concentrations can be achieved with a daily dose of $750 \mathrm{mg}$.

\section{Lack of Clinical Response to Initial Empiric Therapy}

Management of patients with documented or undocumented infection that do not clinically respond to antimicrobial therapy can be challenging [168-171]. The lack of response maybe the result of a pathogen being resistant to the empiric antimicrobial regimen; inadequate serum or tissue levels of the antibiotics; infection at a vascular site (e.g., catheter) or closed space; the emergence of a second infection; or an unusually slow clinical response. Resolutions of fever in patients who are neutropenic are often delayed. Elting et al. reviewed 488 episodes of fever and neutropenia. The median time to fever resolution ranged from 5 to 7 days, and less than $40 \%$ of patients became afebrile before day 5 of therapy [168]. Patients with gram-negative BSI were febrile longer (mean, 6.6-8.2 days), and the time to fever defervescence was even longer for patients with gram-positive BSI (mean, 6.612.4 days). These results are consistent with the findings published by Freifeld et al. who reported that fever persisted a mean of 4 days with ceftazidime therapy, and 3 days when patients were treated with imipenem [169]. Thus, fevers maybe prolonged even when patient is clinically improved, but fever response varies depending upon the specific antibiotic regimen, the site of infection, and the infecting pathogen.

Patients in whom fever persists after 4-5 days of initial antimicrobial therapy should undergo a careful reassessment, and an infectious diseases consultation maybe helpful. Broad-spectrum antibiotics should likely be maximized, but where possible the antibiotics should be adjusted to minimize organ toxicity. The need for additional changes in the empiric therapy should carefully consider the patient's clinical status and the likelihood of early marrow recovery. Although fever resolution may be slow, persistent fever raises concern about an inadequately treated infection [1, 2, 170-172].

Early discontinuation of antibiotics is strongly discouraged in patients when fever and neutropenia persist. In these cases, the clinician should search for additional sources of infection, and CT scans of the chest and/or sinuses may help to identify occult invasive fungal disease. It is clear that patients with persistent marrow suppression are at high-risk for recurrent fever, and/or persistence of "initial infections" or the development of "subsequent infections" [11, 13, 16, 170-172]. Thus antibiotics should be continued until there is evidence of marrow recovery. Clinically stable but febrile patients can be followed carefully without adjusting their antimicrobial treatment. For patients who are persistently febrile and clinically unstable, additional gram-negative bacillary coverage, empiric vancomycin, or empiric broadspectrum antifungal therapy should be considered. However, most physicians begin to consider the use of empiric antifungal therapy (voriconazole, micafungin, or AmBisome) if a patient's fever persists beyond 4-6 days of appropriate antibacterial antibiotics $[11,13]$.

\section{Empiric or Preemptive Antifungal Therapy}

"Empiric" antifungal therapy in this chapter refers to initiation of an antifungal agent at the first evidence of fungal infection, usually persistent or recrudescent fever on or after day 4-6 of empiric antibiotic therapy [1, 2]. "Preemptive" antifungal therapy refers to targeted treatment administered to only those patients with additional findings suggesting invasive fungal infection, such as positive serological tests or abnormal chest CT scan.

Patients with prolonged neutropenia who have received intensive cytotoxic chemotherapy are at risk for invasive fungal infection [173, 174]. Yeast (primarily Candida spp.) and molds typically cause these "subsequent infections," and they are often heralded by persistent or recurrent fever [16]. Since Candida spp. are ubiquitous colonizers of human mucosal surfaces, they may cause mucosal invasion and BSI. Azole prophylaxis has significantly reduced the incidence of invasive $C$. albicans infections, but breakthrough infections due to azole-resistant yeast still occur [175].

Invasive mold infections including aspergillosis (the most common invasive mold infection), zygomycosis, and fusariosis 
occur almost exclusively in high-risk patients with profound neutropenia $\left(\leq 100\right.$ neutrophils $\left./ \mathrm{mm}^{3}\right)$ that has lasted longer than 10 days. At greatest risk are those patients treated for acute myelogenous leukemia for which the incidence of invasive mold infections is 20 times more frequent than what is reported for patients with non-Hodgkins lymphoma and multiple myeloma [175]. Clinical manifestations of occult fungal infection are nonspecific, and because diagnosis of invasive fungal infections is especially difficult, empiric antifungal therapy instituted for persistent neutropenic fever has been the standard approach for several decades $[1,2,171]$. Using these very broad and nonspecific criteria, approximately $22-34 \%$ of neutropenic cancer patients may receive antifungal treatment, but only about $4 \%$ of such patients will ever have an invasive fungal infection identified [176-181]. The choice of empiric antifungal agent must consider not only the most likely fungal pathogens, but also toxicities of the therapy and cost. If antifungal prophylaxis has not been given, then an invasive candida infection is the most likely explanation. For patients receiving fluconazole prophylaxis, fluconazole-resistant candida infections, such as C. krusei or C. glabrata, or an invasive mold infection, are the most common pathogens.

Amphotericin B desoxycholate has historically been the standard empiric antifungal choice, but a number of other antifungal agents including liposomal amphotericin B, itraconazole, voriconazole, and caspofungin appear to be as effective as amphotericin B, and are significantly less toxic [86, 176-180]. There are insufficient data upon which to base a specific empiric antifungal recommendation for patients already receiving mold-active prophylaxis, but a switch to an IV anti-mold agent within a different antifungal class seems prudent. In the absence of CT scan changes and low serum levels of azole prophylaxis, continuing the same mold-active prophylaxis at a higher dosage may also be an acceptable alternative $[91,92,181,182]$.

The development of tests that may detect early fungal infections has prompted an interest in moving away from mandatory empiric antifungal therapy to focused preemptive antifungal treatment. Attempts to date to employ preemptive antifungal therapy have relied on serial serum testing for fungal antigens or DNA, and high-resolution chest CT scan.

Two serum fungal diagnostic tests, the $\beta$-(1-3)-D glucan and the galactomannan test, have been reported to aid in the detection of common invasive fungal infections. The sensitivity of a single serum test using either technique is extremely low, and thus a single negative result should not be used to rule out the diagnosis of an invasive fungal infection. Serial serum monitoring could be used to guide initiation of preemptive antifungal therapy in high-risk patients, but are not recommended for patients at low-risk for invasive fungal infections.

The $\beta$-(1-3)-D glucan test detects most of the relevant fungal pathogens, including Candida spp., Aspergillus spp.,
Pneumocystis spp., and Fusarium spp., but not the zygomycetes or Cryptococcus spp. [183-185]. $\beta-(1-3)-D$ glucan assay was reported in small studies of patients with acute leukemia and myelodysplastic syndrome undergoing therapy to provide early detection of fungal infections, including candidiasis, fusariosis, trichosporonosis, and aspergillosis $[183,185]$. A positive test preceded clinical symptoms of invasive fungal infection in many but not all patients. Experience with use of the $\beta$-(1-3)-D glucan assay in HSCT recipients is limited, and hemodialysis, hemolysis, serum turbidity, hyperlipidemia, visible bilirubin, use of blood products including immunoglobulin and albumin, bacteremia, and the specimen's exposure to gauze may confound interpretation of the test [183, 185].

The galactomannan assay detects only Aspergillus spp. and Penicillium spp., a rare pathogen that on occasion can be invasive [186]. In studies of galactomannan testing the sensitivity has ranged widely among different patient populations $[186,187]$. In patients with hematological malignancies or HSCT recipients, galactomannan sensitivity ranged from 58 to $65 \%$ and specificity from 65 to $95 \%$. The recently reported BMT-CTN prophylaxis trial employed twice-weekly serial galactomannan tests as part of the treatment algorithm [96]. Despite this level of serum galactomannan surveillance, only $56 \%$ of the documented invasive aspergillus infections were detected serum surveillance. When galactomannan tests in this trial did become positive, this occurred a median of only 2 days before the infection was clinically detected [96]. The performance of the galactomannan assay may also be confounded by concomitant use of $\beta$-lactam/ $\beta$-lactamase combinations such as piperacillin-tazobactam (false positives) and anti-mold antifungal agents have been associated with an increase in false-negative results [188].

Chest CT scans may reveal abnormalities in either the lungs or the sinuses that may suggest occult fungal infection. Macro nodules with or without a halo sign are the most typical findings of invasive aspergillosis on chest CT scans [189-191]. The halo sign represents edema or blood surrounding the nodule, and may occur as either an early or late radiographic finding. Other manifestations include nodule(s), wedge-shaped peripheral pneumonitis, or cavitary lesion(s). An air-crescent sign is insensitive and generally appears late if at all.

Preemptive antifungal management, using a combination of clinical symptoms, serological tests, and chest CT scans, has been tested [192]. Maertens et al. used serial serum galactomannan tests and early CT scanning combined with a preemptive treatment algorithm [193]. The preemptive treatment approach resulted in a decrease in the need for empiric antifungal treatment from $35 \%$ vs. $8 \%$, and overall patient survival was similar to that reported with empiric antifungal therapy. More recently, Cordonnier et al. performed a randomized trial that suggests that preemptive antifungal therapy may be potentially a safe alternative to empiric antifungal therapy, for a select group of high-risk neutropenic patients 
that does not include allogeneic transplant recipients [194]. Preemptive therapy in this trial was initiated for clinical symptoms, a chest CT scan that suggested an invasive fungal infection, and/or mycological evidence such as Aspergillus colonization or a positive galactomannan test. Overall survival was similar for both treatment groups, but there were more episodes of invasive fungal infections and a trend toward more fungal-related deaths in those patients treated with preemptive therapy. Finally, Hebart and colleagues compared empiric antifungal therapy versus PCR-driven preemptive antifungal therapy in patients receiving anti-yeast prophylaxis after allogeneic stem cell transplant [195]. This study demonstrated an increased use of antifungal therapy, and a reduced 30-day mortality in the PCR-driven arm, but no differences were reported in the incidence of invasive fungal infections or 100-day survival.

A number of important issues regarding preemptive therapy remain unanswered and require further study. These include the optimal trigger for treatment (clinical or radiological manifestations versus a serum biomarker), which biomarker should be used (antigen or PCR test), timing (early before clinical manifestations or late after clinical manifestations), and which antibiotics provide the most appropriate spectrum of antifungal activity [196-199]. Another important unresolved question is the safety of using preemptive antifungal treatment in patients who are already receiving anti-mold prophylaxis. Though attractive, preemptive antifungal therapy currently remains largely experimental and is not recommended as standard of practice.

\section{Evaluation and Management of Fungal Infections}

Invasive fungal infections remain important problems for patients with hematological malignancies and neutropenia [1, 2, 33, 34, 169, 200]. Several studies have reported progressive increases in the incidence of candidiasis, aspergillus, and other mold infections including zygomycetes, fusarium, pseudoallescheria/scedosporium, and others [201]. Candida spp. are endogenous pathogens to many patients with a hematological malignancy or may be acquired from a wide range of exogenous sources. Mold infections are primarily acquired by the inhalation of aerosolized spores, but additional studies have documented the importance of aerosolized contaminated water sources [202]. The diagnosis of candidiasis and mold infections continues to rely on the recovery of a specific pathogen from cultures of the blood, or identification by culture or histology from tissue samples. Rapid diagnosis of these infections using serum antigen detection as a surrogate marker for invasive disease remains a high priority, but as noted previously this goal has not yet been met [203-205]. Despite recent advances, aspergillosis remains the primary
Table 52.6 Risk factors for candidiasis and aspergillosis after HSCT

\begin{tabular}{llllll}
\hline & \multicolumn{2}{l}{ Candidiasis } & & \multicolumn{2}{l}{ Aspergillosis } \\
\cline { 2 - 3 } & Pre-Azole & Azole Rx & & Early & Late \\
\hline Increased age & Yes & Yes & & No & Yes \\
\hline Unrelated donor & Yes & No & & No & Yes \\
\hline GVHD & Yes & No & & No & Yes \\
\hline Corticosteroids & Yes & No & & No & Yes \\
\hline Neutropenia & Yes & Yes & & Yes & No \\
\hline Season (summer) & No & No & & Yes & No \\
\hline Concomitant infection & Yes & Yes & & Yes & Yes \\
\hline LAF & No & No & & Yes & No \\
\hline Construction & No & No & & No & Yes \\
\hline CMV positive & Yes & Yes & Yes & Yes \\
\hline
\end{tabular}

${ }^{a}$ Multivariate analysis

cause of infection-associated death after allogeneic transplantation and induction therapy for acute leukemia (Table 52.6).

\section{Candidiasis}

Candidemia in neutropenic patients is a life-threatening infection that is associated with acute disseminated candidiasis, a sepsis-like syndrome, multiorgan failure, and death. The incidence of candidiasis has been well documented both before and after the routine use of azole antifungal prophylaxis [37]. Viscoli and coworkers reported the occurrence of candidemia in cancer patients [206]. The overall 30-day mortality rate for infected patients was $39 \%$, and the factors of increased age and stage of disease, the occurrence of septic shock, and the lack of antifungal prophylaxis were associated with an increase in infection-associated death [206]. C. albicans was the most common species identified, but the recovery of nonalbicans species was increased in patients with a hematological malignancy who had received azole prophylaxis. Goodrich and colleagues reported that invasive candida infections occurred in $14 \%$ of transplant recipients before fluconazole prophylaxis was routinely being used. C. albicans $(62 \%)$ and C. tropicalis $(21 \%)$ were the most commonly isolated species, the median time to the development of a Candida spp. BSI was 15 days after transplantation, and these infections had an attributable mortality of $39 \%$ that increased to $88 \%$ when patients had documented Candida tissue invasion [70]. The incidence of invasive candida infections following the introduction of fluconazole prophylaxis decreased to $4.7 \%$. Infections occurred later after transplant (median of 28 days after transplantation), and they were associated with a slightly lower (20\%) mortality rate [37]. Nonalbicans Candida species were more likely to be isolated with $C$. glabrata, and $C$. krusei being most common. $C$. albicans resistance to fluconazole was modest and identified among $5.3 \%$ of C. albicans isolates [37]. 
Treatment of invasive candida infections has evolved with the introduction of new classes of antifungal therapy [207, 208]. Unfortunately, there are no randomized controlled trials of treatment of candidemia in patients with neutropenia, and thus most treatment recommendations are derived from small single-arm studies or subsets of larger randomized trials. Most new antifungal agents are reported to provide success response rates of 55-65\%, but the clinical outcome of these infections is highly dependent on neutrophil recovery [209214]. The IDSA now recommend that an echinocandidin (e.g., caspofungin, anidulafungin, or micafungin) or lipid formulation of amphotericin B be utilized as a first-line therapy for most invasive candida infections [207]. Duration of therapy is dependent on the patient's disease and neutrophil recovery, but minimum therapy for uncomplicated infections is 2 weeks after documented clearance of candida from the blood and resolution of infection-associated symptoms [11-13, 215].

\section{Aspergillosis and Other Mold Infections}

Aspergillus infections involve primarily the respiratory tract (lung and sinuses), but disseminated infection to the central nervous system and other end organs is well described $[33-36,173]$. While invasive infection of the lungs is common, the true incidence of sinus involvement in HSCT recipients is unknown. Extra pulmonary spread of aspergillus is more common when infections occur during periods of neutropenia, while nonneutropenic aspergillus pneumonia is more likely to present with progressive diffuse pneumonitis. Aspergillus fumigatus and flavus are the most frequent clinically important species isolated, but other aspergillus species that are much less common, maybe invasive, but often have less predictable antifungal susceptibilities.

The occurrence of aspergillus infections and critical predisposing factors are clearly outlined by the clinical pattern of aspergillosis after HSCT [33-36, 95]. The pathophysiological conditions and periods that define these infections begin with neutropenia during the preengraftment period (Table 52.6). The second period of infection spans day 40-120 posttransplantation when patients suffer from a cellular immune defect induced primarily by acute graft versus host disease (GVHD), and/or the immunosuppressant therapy needed to control GVHD. The third period of aspergillus infection occurs late after transplantation and these infections are correlated with late-CMV disease and chronic GVHD. These later entities are surrogate markers of delayed immune reconstitution after transplantation. Mortality with invasive aspergillus after transplantation has historically been very high, ranging from 60 to $88 \%$, and similar for all three-infection periods [1, 2, 33-36]. Clinical characteristics and outcomes of aspergillus infections among patients with a hematological malignancy treated with conventional therapy are similar to HSCT recipients [35]. Pulmonary involvement is seen in most cases $(87 \%)$, infection of the sinuses/nose occurs in $16 \%$ of cases, and dissemination to the brain occurs in $8 \%$ of infected patients $[35,216,217]$. Mortality has also been very high $(64 \%)$ for this patient population, although slightly lower death rates have been reported for patients with AML who experience resolution of their neutropenia $(30-40 \%)[1,2,217]$.

Diagnosis, prevention, and treatment of aspergillus infections remain inadequate. Diagnosis is dependent on a high index of suspicion and recovery of the infecting organism by histology or microbiology from tissue specimens or pulmonary or sinus lavage. Results of galactomannan assays as a tool for early detection are controversial but a positive result has been associated with high specificity [203]. While surveillance cultures are no longer utilized, the isolation of A. fumigatus or flavus in respiratory specimens or nasal secretions has been shown to be highly predictive of present or future invasive aspergillus infections [1, 2]. Mucosal eschars along the nasal septum are important clinical clues to the diagnosis of aspergillus sinusitis. Biopsy and culture of such lesions are always indicated. If nasal lesions are not observed, but CT scans show sinusitis, then sinus lavage and biopsy may establish the presence of fungal pathogens and preclude the need for further diagnostic procedures.

BAL is the standard approach for initial evaluation of pulmonary lesions, but a BAL is a less sensitive procedure if the pulmonary lesions are focal, small, and/or peripherally located. The sensitivity of a BAL to diagnose Aspergillus is at best $50-60 \%$, and thus a negative procedure does not exclude the diagnosis of Aspergillus [218-220]. Preliminary work has suggested that galactomannan detection in BAL fluid may be a useful adjunct, and early results suggest excellent specificity and improved sensitivity when compared to serum testing ( $80 \%$ vs. $50 \%$ respectively) [218]. PCR assays for fungal detection in blood and BAL fluid are also being developed and tested, but none are commercially available [221]. Open lung biopsy is usually reserved for patients with a negative BAL, or for patients in which the disease is progressive and a diagnosis must be immediately established. A thoracoscopic approach is utilized when possible because of lowered procedure morbidity, but tissue biopsy from both peripheral and central areas of abnormal lung are recommended because of the focal nature of Aspergillus infections.

Treatment of established Aspergillus infection has improved but remains inadequate. Early diagnosis and treatment remains critical, as does resolution of neutropenia or other immunosuppression. Prolonged (8-10 weeks) and high-dose (1.0-1.5 mg/kg/day) amphotericin B or an equivalent dose of a lipid formulation of amphotericin B was standard initial treatment until voriconazole was developed and tested [222]. Early this decade Herbecht et al. studied patients 
with hematological malignancy and HSCT recipients who were infected with aspergillus. Study participants were randomized to treatment with voriconazole or amphotericin B desoxycolate [223]. Voriconazole recipients had improved survival (71 \% vs. $58 \%$ ) and improved overall infection response rates ( $53 \%$ vs. $32 \%$ ). Even more important was the finding that voriconazole efficacy was maintained for infected patients with persistent neutropenia or for allogeneic transplant recipients. Voriconazole-associated toxicity was less than what was seen with amphotericin B desoxycolate, and now voriconazole is the recommended first-line therapy for aspergillosis.

The echinocandins are a class of antifungal agents with enhanced activity against Aspergillus and fluconazoleresistant yeast, but lack activity against the zygomycetes (Rhizopus/Mucor) [224]. Caspofungin, the first of the class to receive FDA approval demonstrated approximately a $40 \%$ response rate among patients with aspergillosis who were found to be intolerant or refractory to conventional therapy [224]. Toxicity with these agents has been relatively low, and preliminary in vitro and preclinical animal studies suggest that echinocandins may be excellent agents for use in combination with an azole or amphotericin B product to enhance the antifungal efficacy [225, 226].

Posaconazole, another azole antifungal antibiotic with enhanced activity against Aspergillus, is available in only an oral formulation. Posaconazole has shown encouraging activity as salvage therapy for aspergillosis, but more importantly it appears to have substantial clinical efficacy as treatment for infections caused by zygomycetes [227-230].

The role of surgery as an adjunct to antimicrobial treatment for pulmonary Aspergillus remains controversial, but a published analysis showed little survival benefit if surgical resection of the clinically apparent infection was performed [231]. The role of surgery for localized skin and soft tissue, bone and isolated CNS lesions remains unclear and controversial, but could be considered for selected patients based on their clinical status and infection [228, 232].

The management of invasive aspergillus and mold fungal infections in patients with hematological malignancy or after HSCT continues to raise several critical clinical questions including:

1. What is the optimal antifungal treatment for clinical infections without a documented fungal pathogen?

2. What is the role for combinations of antifungal antibiotics?

3. Is amphotericin-B still the treatment of choice for zygomycetes infections?

4. Can azole antifungal agents with anti-mold activity be used safely when administered concomitantly with immunosuppressant agents including tacrolimus and sirolimus. A new fever coupled with a pulmonary nodule or infiltrate that develops during antibiotic treatment of fever and neutro- penia is suggestive of a mold infection. Aspergillus is by far the most common mold, but other molds including zygomycetes (mucor/rhizopus and others resistant to voriconazole), fusarium, and pseudoallescheria/scedosporium must be considered. The clinical presentations of these different molds are quite similar, and one factor that has been identified as a risk factor for zygomycosis is voriconazole prophylaxis or treatment. Most experts believe that empiric treatment that is to be directed primarily against aspergillosis should consist of voriconazole [222, 223]. Voriconazole has a much lower toxicity profile than amphotericin B products, and unlike posaconazole is available in both an oral and IV formulation. Unfortunately, voriconazole lacks antimicrobial activity against zygomycosis and for patients already receiving voriconazole the clinician must then consider the need for empiric coverage of zygomycetes [233-235]. The decision to prescribe treatment directed against zygomycosis has in the past relied exclusively on an amphotericin B products, but posaconazole maybe now a more attractive treatment alternative for such infections [235, 236].

It is not known which empiric antifungal regimen results in the best patient outcomes. Invasive mold infections may progress quickly during periods of neutropenia, and thus despite the lack of definitive prospective data the concept of empiric combination antifungal therapy has become clinically attractive but remains controversial [237-239]. Evidence from animal studies of invasive aspergillosis suggests that the combination of an azole and echinocandin is superior to treatment with an azole alone. Retrospective clinical studies in humans also provide some additional support for combination therapy [237-239]. The primary arguments against combination therapy rest with concern about toxicity and cost. Despite these issues many experts frequently will prescribe initial treatment with voriconazole plus caspofungin, or liposomal amphotericin B and caspofungin [240]. Combination of agents from all three classes (an azole, amphotericin B, and echinocandin) of antifungal therapy could be combined, but there are animal model and laboratory data that suggest potential antagonism when such combinations are utilized. To date there are no clinical data that support or refute such combination treatment.

Not all patients with invasive aspergillosis will respond to treatment with azole antibiotics like voriconazole or posaconazole. One possible explanation for this clinical failure maybe that not all patients achieve adequate serum levels with the oral formulation of these medications [182, 241, 242]. There is ample evidence showing inter-individual variability when oral voriconazole dosing is utilized, and this has resulted in the recommendation that voriconazole or posaconazole serum levels be monitored in patients whose infections appears to be failing to respond. However, clinical availability of voriconazole and posaconazole serum levels in many centers is limited, and thus some experts just increase 
the administered daily voriconazole or posaconazole dose, or switch to IV voriconazole therapy when there is concern about a patient's clinical response or a patient's absorption of oral medications is questioned.

Empiric treatment does not replace the need for implementation of aggressive methods to identify a specific etiological diagnosis, and thus many of these patients must undergo additional diagnostic procedures to identify the pathogenic organism. This is even more important as we have to consider pathogen-specific therapy for infections caused by pathogens like the zygomycetes. Amphotericin B desoxycolate and lipid formulation products have been the gold standard for the treatment of zygomycosis, but clinical results have been very disappointing [222, 235]. Some experts believe that the poor clinical response with amphotericin B therapy is a reflection of insufficient dosage, but randomized studies have reported that $10 \mathrm{mg} / \mathrm{kg} /$ day of liposomal amphotericin B to be no more effective than $3 \mathrm{mg} / \mathrm{kg} / \mathrm{day}$ when treating confirmed mold infections [240]. Posaconazole has activity against many of the zygomycetes, and based on early anecdotal experience suggesting success makes posaconazole therapy a potentially attractive and less toxic alternative to amphotericin B treatment [236].

Finally is the question pertaining to the concomitant use of azole antifungal agents and immunosuppressive agents like cyclosporine, tacrolimus, or sirolimus. Such combination therapy with cyclosporine and tacrolimus can be challenging, but schemes that define appropriate dose adjustment have been developed that allows the successful co-administration of azole antifungal agents and some of the calcineurin inhibitors when frequent monitoring of serum levels is incorporated into the patient's clinical care. The more difficult clinical scenario is the management of patients who are to receive concomitant voriconazole or posaconazole and sirolimus. There is a package insert "black box warning" that emphasizes the deleterious interaction between these drugs, and it is well known that voriconazole therapy significantly increases the serum levels of sirolimus [243]. Yet, the need to prescribe voriconazole/posaconazole for some patients receiving sirolimus is critical. Thus it is suggested that by reducing the sirolimus dose by $90 \%$ and carefully monitoring serum levels, these agents can be successfully co-administrated.

\section{Myeloid Colony-Stimulating Factors}

Prophylactic use of myeloid colony-stimulating factors (CSFs) has been shown to reduce the incidence of neutropenic fever, and reduced infection-related mortality and all-cause mortality [11, 13, 244, 245]. Authoritative evidencebased guidelines have indicated that clinical benefits from prophylactic CSFs accrue when the risk of neutropenic fever associated with a chemotherapy regimen is $20 \%$ or greater, unless the cancer treatment is symptomatic or palliative, or when dose reduction is the clinically appropriate approach [246-248]. Due to the high cost of CSFs, it is not clear that CSF prophylaxis given widely to all patients at the threshold of $20 \%$ risk of fever and neutropenia is cost-effective for all healthcare markets [249-251]. If societal costs are considered, the economic impact of fever and neutropenia becomes more apparent, and it may be easier to recognize the costsaving benefits of CSFs [251]. Primary prophylaxis - the use of CSFs for prevention in the first cycle of treatment for many lymphoid hematological malignancies-does appear to reduce the incidence of fever and neutropenia and is likely to be most cost-effective. Primary CSF prophylaxis should not routinely be administered to patients with myeloid hematological malignancies. CSF prophylaxis should be preferentially considered for older patients, or if patients have additional infection risk factors, including prior episodes of fever and neutropenia, poor nutritional or performance status, no antibiotic prophylaxis, significant co-morbid medical conditions, or other modifying disease characteristics that suggests there is substantial risk of fever and/or severe infection during neutropenia [252-254]. Treatment with CSFs is not recommended when the risk of fever and neutropenia is $10 \%$ or less. If given, CSF treatment should be started immediately after the chemotherapy is completed.

Myeloid CSFs are not recommended as adjuncts to antibiotics for treating established fever and neutropenia or infection [255-258]. Although days of neutropenia, duration of fever, and length of hospital stay have been minimally decreased in some randomized studies, the actual clinical benefit of these reductions has been quite small and none of the studies have demonstrated a survival benefit with therapeutic CSFs [255-258]. Thus, given the cost and adverse effects of the CSFs, and the lack of consistent clinical efficacy, the addition of G-CSF or GM-CSF at the onset of fever and neutropenia is not recommended.

\section{Summary}

The morbidity and mortality of "initial infections" for patients with a hematological malignancy have dramatically decreased, but during this same time period there has been the emergence of antibiotic-resistant bacteria, and a significant increase in the incidence of fungal infections. Antibiotics have improved and in general are less toxic than their ancestors. Progress has been made in the area of prophylaxis of Candida albicans infections and potentially aspergillosis. Yet, patients now are at an increased risk of nonalbicans yeast infections and the mortality from mold infections (e.g., aspergillus, zygomycetes) remains significant. The promise of new diagnostic techniques, additional antimicrobial agents, and strategies for treatment and prophylaxis of "high-risk" 
patients with hematological malignancy holds the potential that cancer treatment for such patients may be safer in the future. It is critical for the oncology team to remember that infections are a dynamic process and change is guaranteed. Physicians who manage patients with a hematological malignancy must not forget the value and importance of standard infection control measures. However, it will be a challenge to maintain such infection control approaches as the care of these patients continues to be transferred to an ambulatory/ day hospital facility.

\section{References}

1. Pizzo PA. Management of fever in patients with cancer and treatment-induced neutropenia. N Engl J Med. 1993;328:1323-32.

2. Wade JC. Management of infection in patients with acute leukemia. Hematol Oncol Clin North Am. 1993;7:293-315.

3. Maki DG, Kluger DM, Crnich CJ. The risk of bloodstream infection in adults with different intravascular devices: a systematic review of 200 published prospective studies. Mayo Clin Proc. 2006;81:1159-71.

4. Wade JC. Viral infections in patients with hematological malignancy. Hematology. 2006;2006(1):368-74.

5. Rolston KV. New trends in patient management: risk-based therapy for febrile patients with neutropenia. Clin Infect Dis. 1999;29:515-21.

6. Talcott JA, Siegel RD, Finberg R, Goldman L. Risk assessment in cancer patients with fever and neutropenia: a prospective, twocenter validation of a prediction rule. J Clin Oncol. 1992;10: 316-22.

7. Klastersky J, Paesmans M, Rubenstein EB, Boyer M, Elting L, Feld R, Gallagher J, Herrstedt J, Rapoport B, Rolston K, Talcott J. The Multinational Association for Supportive Care in Cancer risk index: a multinational scoring system for identifying low-risk febrile neutropenic cancer patients. J Clin Oncol. 2000;18: 3038-51.

8. Klastersky J. Management of fever in neutropenic patients with different risks of complications. Clin Infect Dis. 2004;39 Suppl $1:$ S32-7.

9. Schimpff SC. Empiric antibiotic therapy for granulocytopenic cancer patients. Am J Med. 1986;80(Suppl 5c):13-20.

10. Bodey GP, Buckley M, Sathe YS, Freireich EJ. Quantitative relationships between circulating leukocytes and infection in patients with acute leukemia. Ann Intern Med. 1966;64:328-40.

11. Freifeld AG, Bow EJ, Sepkowitz KA, Boeckh MJ, Ito JI, Mullen CA, Raad II, Rolston KV, Young JA, Wingard JR, Infectious Diseases Society of America. Clinical practice guidelines for the use of antimicrobial agents in the neutropenic patients with cancer: 2010 update by the IDSA. Clin Infect Dis. 2011; 52:e56-93.

12. Tomblyn M, Chiller T, Einsele H, Gress R, Sepkowitz K, Storek J, Wingard JR, Young JA, Boeckh MJ, Center for International Blood and Marrow Research, National Marrow Donor program, European Blood and Marrow Transplant Group, American Society of Blood and Marrow Transplantation, Canadian Blood and Marrow Transplant Group, Infectious Diseases Society of America, Society for Healthcare Epidemiology of America, Association of Medical Microbiology and Infectious Disease Canada, Centers for Disease Control and Prevention. Guidelines for prevention of infectious complications among hematopoietic cell transplants recipients: a global perspective. Biol Blood Marrow Transplant. 2009;15:1143-238.
13. National Comprehensive Cancer Network Practice Guidelines in Oncology -v.2.2009, Prevention and treatment of Cancer-Related Infections; 2009.

14. Zinner SH. Changing epidemiology of infections in patients with neutropenia and cancer: emphasis on gram-positive and resistant bacteria. Clin Infect Dis. 1999;29:490-4.

15. Wisplinghoff H, Seifert H, Wenzel RP, Edmond MB. Current trends in the epidemiology of nosocomial bloodstream infections in patients with hematological malignancies and solid neoplasms in hospitals in the United States. Clin Infect Dis. 2003;36:1103-10.

16. Wingard JR, Santos GW, Saral R. Differences between first and subsequent fevers during prolonged neutropenia. Cancer. 1987; 59:844-9.

17. Morris PG, Hassan T, McNamara M, Hassan A, Wiig R, Grogan L, Breathnach OS, Smyth E, Humphreys H. Emergence of MRSA in positive blood cultures from patients with febrile neutropenia-a cause for concern. Support Care Cancer. 2008;16:1085-8.

18. Weinstock DM, Conlon M, Iovino C, Aubrey T, Gudiol C, Riedel E, Young JW, Kiehn TE, Zuccotti G. Colonization. bloodstream infection, and mortality caused by vancomycin-resistant enterococcus early after allogeneic hematopoietic stem cell transplant. Biol Blood Marrow Transplant. 2007;13:615-22.

19. Engelhard D, Elishoov H, Strauss N, Naparstek E, Nagler A, Simhon A, Raveh D, Slavin S, Or R. Nosocomial coagulase-negative staphylococcal infections in bone marrow transplantation recipients with central vein catheter: a 5-year prospective study. Transplantation. 1996;61:430-4.

20. Villablanca JG, Steiner M, Kersey J, Ramsay NK, Ferrieri P, Haake R, Weisdorf D. The clinical spectrum of infections with viridans streptococci in bone marrow transplant recipients. Bone Marrow Transplant. 1990;6:387-93.

21. Classen DC, Burke JP, Ford CD, Evershed S, Aloia MR, Wilfahrt JK, Elliott JA. Streptococcus mitis sepsis in bone marrow transplant patients receiving oral antimicrobial prophylaxis. Am J Med. 1990;89:441-6.

22. Elting LS, Bodey GP, Keefe BH. Septicemia and shock syndrome due to viridans streptococci: a case control study of predisposing factors. Clin Infect Dis. 1992;14:1201-7.

23. Therriault BL, Wilson JW, Barreto JN, Estes LL. Characterization of bacterial infections in allogeneic hematopoietic stem cell transplant recipients who received prophylactic levofloxacin with either penicillin or doxycycline. Mayo Clin Proc. 2010;85:711-8.

24. Edmond MB, Ober JF, Dawson JD, Weinbaum DL, Wenzel RP. Vancomycin-resistant enterococcal bacteremia: natural history and attributable mortality. Clin Infect Dis. 1996;23:1234-9.

25. Martin MA, Pfaller MA, Wenzel RP. Coagulase-negative staphylococcal bacteremia: mortality and hospital stay. Ann Intern Med. 1989;110:9-16.

26. Wenzel RP. Perspective: attributable mortality - the promise of better antimicrobial therapy. J Infect Dis. 1989;178:917-9.

27. Kamboj M, Chung D, Seo SK, et al. The change in epidemiology of vancomycin-resistant enterococcus (VRE) bacteremia in allogeneic HSCT recipients. Biol Blood Marrow Transplant. 2010;16:1576-81.

28. Elting LS, Rubenstein EB, Rolston KV, Bodey GP. Outcomes of bacteremia in patients with cancer and neutropenia. Clin Infect Dis. 1997;25:247-59.

29. Cattaneo C, Quaresmini G, Casari S, Capucci MA, Micheletti M, Borlenghi E, Signorini L, Re A, Carosi G, Rossi G. Recent changes in bacterial epidemiology and the emergence of fluoroquinoloneresistant Escherichia coli among patients with haematological malignancies: results of a prospective study on 823 patients at a single institution. J Antimicrob Chemother. 2008;61:721-8.

30. Oliveira AL, de Souza M, Carvalho-Dias VM, Ruiz MA, Silla L, Tanaka PY, Simões BP, Trabasso P, Seber A, Lotfi CJ, Zanichelli MA, Araujo VR, Godoy C, Maiolino A, Urakawa P, Cunha CA, 
de Souza CA, Pasquini R, Nucci M. Epidemiology of bacteremia and factors associated with multi-drug-resistant gram-negative bacteremia in hematopoietic stem cell transplant recipients. Bone Marrow Transplant. 2007;39:775-81.

31. Johnson MP, Ramphal R. Beta-lactam-resistant Enterobacter bacteremia in febrile neutropenic patients receiving monotherapy. J Infect Dis. 1990;162:981.

32. Brown AE, Kiehn TE, Armstrong DE. Bacterial resistance in patients with neoplastic disease. Infect Dis Clin Pract. 1995;4(Suppl3):S136-44.

33. Wald A, Leisenring W, Van Burik JA, Bowden RA. Epidemiology of Aspergillus infections in a large cohort of patients undergoing bone marrow transplantation. J Infect Dis. 1997;175:1459-66.

34. Marr KA, Carter RA, Boeckh M, Martin P, Corey L. Invasive aspergillosis in allogeneic stem cell transplant recipients: changes in epidemiology and risk factors. Blood. 2002;100:4358-66.

35. Patterson TF, Kirkpatrick WR, White M, Hiemenz JW, Wingard JR, Dupont B, Rinaldi MG, Stevens DA, Graybill JR. Invasive aspergillosis: disease spectrum, treatment practices, and outcomes. I3 Aspergillus Study Group. Medicine (Baltimore). 2000;79: 250-60.

36. Baddley JW, Andes DR, Marr KA, Kontoyiannis DP, Alexander BD, Kauffman CA, Oster RA, Anaissie EJ, Walsh TJ, Schuster MG, Wingard JR, Patterson TF, Ito JI, Williams OD, Chiller T, Pappas PG. Factors associated with mortality in transplant patients with invasive aspergillosis. Clin Infect Dis. 2010;50:1559-67.

37. Marr KA, Seidel K, White TC, Bowden RA. Candidemia in allogeneic blood and marrow transplant recipients: evolution of risk factors after the adoption of prophylactic fluconazole. J Infect Dis. 2000;181:309-16.

38. Boyce JM, Pittet D. Guideline for hand hygiene in health-care settings. Recommendations of the Healthcare Infection Control Practices Advisory Committee and the HICPAC/SHEA/APIC/ IDSA Hand Hygiene Task Force. Society for Healthcare Epidemiology of America/Association for Professionals in Infection Control/Infectious Diseases Society of America. MMWR Recomm Rep. 2002;51:1-45.

39. Oughton MT, Loo V, Dendukri G, Dendukuri N, Fenn S, Libman MD. Hand hygiene with soap and water is superior to alcohol rubs and antiseptic handwipes for removal of $C$. difficile. Infect Control Hosp Epidemiol. 2010;31:571-3.

40. Siegel JD, Rhinehart E, Jackson M, Chiarello L, Health Care Infection Control Practices Advisory Committee. 2007 Guideline for isolation precautions: preventing transmission of infectious agents in health care settings. Am J Infect Control. 2007;35:S65-164.

41. Pronovost P, Needham D, Berenholtz S, Sinopoli D, Chu H, Cosgrove S, Sexton B, Hyzy R, Welsh R, Roth G, Bander J, Kepros J, Goeschel C. An intervention to decrease catheter-related bloodstream infections in the ICU. N Engl J Med. 2006;355: 2725-32.

42. Bodey GP. The treatment of febrile neutropenia: from the Dark Ages to the present. Support Care Cancer. 1997;5:351-7.

43. Bow EJ. Management of the febrile neutropenic cancer patient: lessons from 40 years of study. Clin Microbiol Infect. 2005;11 Suppl 5:24-9.

44. Cruciani M, Rampazzo R, Malena M, Lazzarini L, Todeschini G, Messori A, Concia E. Prophylaxis with fluoroquinolones for bacterial infections in neutropenic patients: a meta-analysis. Clin Infect Dis. 1996;23:795-805.

45. Cruciani M, Malena M, Bosco O, Nardi S, Serpelloni G, Mengoli C. Reappraisal with meta-analysis of the addition of Gram-positive prophylaxis to fluoroquinolone in neutropenic patients. J Clin Oncol. 2003;21:4127-37.

46. Rotstein C, Mandell LA, Goldberg N. Fluoroquinolone prophylaxis for profoundly neutropenic cancer patients: a meta-analysis. Opin Oncol. 1997;4:2-7.
47. Gafter-Gvili A, Fraser A, Paul M, Leibovici L. Meta-analysis: antibiotic prophylaxis reduces mortality in neutropenic patients. Ann Intern Med. 2005;142:979-95.

48. Engels EA, Lau J, Barza M. Efficacy of quinolone prophylaxis in neutropenic cancer patients: a meta-analysis. J Clin Oncol. 1998;16:1179-87.

49. van de Wetering MD, de Witte MA, Kremer LC, Offringa M, Scholten RJ, Caron HN. Efficacy of oral prophylactic antibiotics in neutropenic afebrile oncology patients: a systematic review of randomised controlled trials. Eur J Cancer. 2005;41:1372-82.

50. Baden LR. Prophylactic antimicrobial agents and the importance of fitness. N Engl J Med. 2005;353:1052-4.

51. van Belkum A, Vos MC. Prophylactic application of fluoroquinolones for selective decontamination of the gut: friend or foe. Eur J Clin Microbiol Infect Dis. 2005;24:109-10.

52. Almyroudis NG, Segal BH. Antibacterial prophylaxis in patients with cancer and neutropenia. N Engl J Med. 2006;354:90-4; author reply $90-4$.

53. Pasqualotto AC, Rosa DD, Machado AL. Antibacterial prophylaxis in patients with cancer and neutropenia. N Engl J Med. 2006;354:90-4; author reply 90-4.

54. Dykewicz CA. Summary of the guidelines for preventing opportunistic infections among hematopoietic stem cell transplant recipients. Clin Infect Dis. 2001;33:139-44.

55. Masaoka T. Evidence-based recommendations for antimicrobial use in febrile neutropenia in Japan: executive summary. Clin Infect Dis. 2004;39 Suppl 1:S49-52.

56. Bucaneve G, Micozzi A, Menichetti F, Martino P, Dionisi MS, Martinelli G, Allione B, D'Antonio D, Buelli M, Nosari AM, Cilloni D, Zuffa E, Cantaffa R, Specchia G, Amadori S, Fabbiano F, Deliliers GL, Lauria F, Foà R, Del Favero A, Gruppo Italiano Malattie Ematologiche dell'Adulto (GIMEMA) Infection Program. Levofloxacin to prevent bacterial infection in patients with cancer and neutropenia. N Engl J Med. 2005;353:977-87.

57. Cullen M, Steven N, Billingham L, Gaunt C, Hastings M, Simmonds P, Stuart N, Rea D, Bower M, Fernando I, Huddart R, Gollins S, Stanley A, Simple Investigation in Neutropenic Individuals of the Frequency of Infection after Chemotherapy +/Antibiotic in a Number of Tumours (SIGNIFICANT) Trial Group. Antibacterial prophylaxis after chemotherapy for solid tumors and lymphomas. N Engl J Med. 2005;353:988-98.

58. Leibovici L, Paul M, Cullen M, Bucaneve G, Gafter-Gvili A, Fraser A, Kern WV. Antibiotic prophylaxis in neutropenic patients: new evidence, practical decisions. Cancer. 2006;107:1743-51.

59. Reuter S, Kern WV, Sigge A, Döhner H, Marre R, Kern P, von Baum H. Impact of fluoroquinolone prophylaxis on reduced infection-related mortality among patients with neutropenia and hematologic malignancies. Clin Infect Dis. 2005;40:1087-93.

60. Ito JI, Tegtmeier BR, O’Donnell MR. Antibacterial prophylaxis in patients with cancer and neutropenia. N Engl J Med. 2006;354:904; author reply 90-4.

61. Kern WV, Klose K, Jellen-Ritter AS, Oethinger M, Bohnert J, Kern P, Reuter S, von Baum H, Marre R. Fluoroquinolone resistance of Escherichia coli at a cancer center: epidemiologic evolution and effects of discontinuing prophylactic fluoroquinolone use in neutropenic patients with leukemia. Eur J Clin Microbiol Infect Dis. $2005 ; 24: 111-8$.

62. Gomez L, Garau J, Estrada C, Marquez M, Dalmau D, Xercavins M, Martí JM, Estany C. Ciprofloxacin prophylaxis in patients with acute leukemia and granulocytopenia in an area with a high prevalence of ciprofloxacin-resistant Escherichia coli. Cancer. 2003;97:419-24.

63. Martino R, Subira M, Altes A, et al. Effect of discontinuing prophylaxis with norfloxacin in patients with hematologic malignancies and severe neutropenia. A matched case-control study of the effect on infectious morbidity. Acta Haematol. 1998;99:206-11.

64. Gasink LB, Fishman NO, Weiner MG, Nachamkin I, Bilker WB, Lautenbach E. Fluoroquinolone-resistant Pseudomonas aeruginosa: 
assessment of risk factors and clinical impact. Am J Med. 2006; 119:526e19-25.

65. Kaye KS, Kanafani ZA, Dodds AE, Engemann JJ, Weber SG, Carmeli Y. Differential effects of levofloxacin and ciprofloxacin on the risk for isolation of quinolone-resistant Pseudomonas aeruginosa. Antimicrob Agents Chemother. 2006;50:2192-6.

66. Muto CA, Pokrywka M, Shutt K, Mendelsohn AB, Nouri K, Posey K, Roberts T, Croyle K, Krystofiak S, Patel-Brown S, Pasculle AW, Paterson DL, Saul M, Harrison LH. A large outbreak of Clostridium difficile-associated disease with an unexpected proportion of deaths and colectomies at a teaching hospital following increased fluoroquinolone use. Infect Control Hosp Epidemiol. $2005 ; 26: 273-80$

67. Pepin J, Saheb N, Coulombe MA, Alary ME, Corriveau MP, Authier S. Emergence of fluoroquinolones as the predominant risk factor for Clostridium difficile-associated diarrhea: a cohort study during an epidemic in Quebec. Clin Infect Dis. 2005;41:1254-60.

68. No authors listed. Reduction of fever and streptococcal bacteremia in granulocytopenic patients with cancer. A trial of oral penicillin V or placebo combined with pefloxacin. International Antimicrobial Therapy Cooperative Group of the European Organization for Research and Treatment of Cancer. JAMA. 1994; 272:1183-9.

69. Ribaud P, Chastang C, Latage JP, Baffroy-Lafitte L, Parquet N, Devergie A, Espérou H, Sélimi F, Rocha V, Espérou H, Sélimi F, Rocha V, Derouin F, Socié G, Gluckman E. Survival and prognostic factors of invasive aspergillosis after allogeneic bone marrow transplantation. Clin Infect Dis. 1999;28:322-30.

70. Goodrich JM, Reed EC, Mori M, Fisher LD, Skerrett S, Dandliker PS, Klis B, Counts GW, Meyers JD. Clinical features and analysis of risk factors for invasive candidal infection after marrow transplantation. J Infect Dis. 1991;164:731-40.

71. VanBurik JH, Weisdorf DJ. Infections in recipients of blood and marrow transplantation. Hematol/Oncol Clin North Am. 1991;13:1065-89.

72. Segal BH, Almyroudis NG, Battiwalla M, Herbrecht R, Perfect JR, Walsh TJ, Wingard JR. Prevention and early treatment of invasive fungal infection in patients with cancer and neutropenia and in stem cell transplant recipients in the era of newer broad-spectrum antifungal agents and diagnostic adjuncts. Clin Infect Dis. 2007;44:402-9.

73. Kanda Y, Yamamoto R, Chizuka A, Hamaki T, Suguro M, Arai C, Matsuyama T, Takezako N, Miwa A, Kern W, Kami M, Akiyama H, Hirai H, Togawa A. Prophylactic action of oral fluconazole against fungal infection in neutropenic patients. A meta-analysis of 16 randomized, controlled trials. Cancer. 2000;89:1611-25.

74. Goodman JL, Winston DJ, Greenfield RA, Chandrasekar PH, Fox B, Kaizer H, Shadduck RK, Shea TC, Stiff P, Friedman DJ. A controlled trial of fluconazole to prevent fungal infections in patients undergoing bone marrow transplantation. N Engl J Med. 1992;326:845-51

75. Slavin MA, Osborne B, Adams R, Levenstein MJ, Schoch HG, Feldman AR, Meyers JD, Bowden RA. Efficacy and safety of fluconazole prophylaxis for fungal infections after marrow transplantation-a prospective, randomized, double-blind study. J Infect Dis. 1995; 171:1545-52.

76. Rotstein C, Bow EJ, Laverdiere M, Ioannou S, Carr D, Moghaddam N. Randomized placebo-controlled trial of fluconazole prophylaxis for neutropenic cancer patients: benefit based on purpose and intensity of cytotoxic therapy. The Canadian Fluconazole Prophylaxis Study Group. Clin Infect Dis. 1999;28:331-40.

77. Bow EJ, Laverdiere M, Lussier N, Rotstein C, Cheang MS, Ioannou S. Antifungal prophylaxis for severely neutropenic chemotherapy recipients: a meta analysis of randomized-controlled clinical trials. Cancer. 2002;94:3230-46.

78. Robenshtok E, Gafter-Gvili A, Goldberg E, Weinberger M, Yeshurun M, Leibovici L, Paul M. Antifungal prophylaxis in cancer patients after chemotherapy or hematopoietic stem-cell transplantation: systematic review and meta-analysis. J Clin Oncol. 2007;25:5471-89.

79. van Burik JA, Ratanatharathorn V, Stepan DE, Miller CB, Lipton JH, Vesole DH, Bunin N, Wall DA, Hiemenz JW, Satoi Y, Lee JM, Walsh TJ, National Institute of Allergy and Infectious Diseases Mycoses Study Group. Micafungin versus fluconazole for prophylaxis against invasive fungal infections during neutropenia in patients undergoing hematopoietic stem cell transplantation. Clin Infect Dis. 2004;39:1407-16.

80. Vardakas KZ, Michalopoulos A, Falagas ME. Fluconazole versus itraconazole for antifungal prophylaxis in neutropenic patients with haematological malignancies: a meta-analysis of randomisedcontrolled trials. Br J Haematol. 2005;131:22-8.

81. Hachem R, Hanna H, Kontoyiannis D, Jiang Y, Raad I. The changing epidemiology of invasive candidiasis: Candida glabrata and Candida krusei as the leading causes of candidemia in hematologic malignancy. Cancer. 2008;112:2493-9.

82. Marr KA, Seidel K, Slavin MA, Bowden RA, Schoch HG, Flowers ME, Corey L, Boeckh M. Prolonged fluconazole prophylaxis is associated with persistent protection against candidiasis-related death in allogeneic marrow transplant recipients: long-term follow-up of a randomized, placebo-controlled trial. Blood. 2000;96:2055-61.

83. Mattiuzzi GN, Alvarado G, Giles FJ, Ostrosky-Zeichner L, Cortes J, O'brien S, Verstovsek S, Faderl S, Zhou X, Raad II, Bekele BN, Leitz GJ, Lopez-Roman I, Estey EH. Open-label, randomized comparison of itraconazole versus caspofungin for prophylaxis in patients with hematologic malignancies. Antimicrob Agents Chemother. 2006;50:143-7.

84. Ullmann AJ, Lipton JH, Vesole DH, Chandrasekar P, Langston A, Tarantolo SR, Greinix H, Morais deA zevedo W, Reddy V, Boparai N, Pedicone L, Patino H, Durrant S. Posaconazole or fluconazole for prophylaxis in severe graft-versus-host disease. N Engl J Med. 2007;356:335-47.

85. Cornely OA, Maertens J, Winston DJ, Perfect J, Ullmann AJ, Walsh TJ, Helfgott D, Holowiecki J, Stockelberg D, Goh YT, Petrini M, Hardalo C, Suresh R, Angulo-Gonzalez D. Posaconazole vs. fluconazole or itraconazole prophylaxis in patients with neutropenia. N Engl J Med. 2007;356:348-59.

86. Glasmacher A, Prentice A, Gorschluter M, Engelhart S, Hahn C, Djulbegovic B, Schmidt-Wolf IG. Itraconazole prevents invasive fungal infections in neutropenic patients treated for hematologic malignancies: evidence from a meta-analysis of 3,597 patients. J Clin Oncol. 2003;21:4615-26.

87. Marr KA, Crippa F, Leisenring W, Hoyle M, Boeckh M, Balajee SA, Nichols WG, Musher B, Corey L. Itraconazole versus fluconazole for prevention of fungal infections in patients receiving allogeneic stem cell transplants. Blood. 2004;103: $1527-33$

88. Winston DJ, Maziarz RT, Chandrasekar PH, Lazarus HM, Goldman M, Blumer JL, Leitz GJ, Territo MC. Intravenous and oral itraconazole versus intravenous and oral fluconazole for longterm antifungal prophylaxis in allogeneic hematopoietic stem-cell transplant recipients. A multicenter, randomized trial. Ann Intern Med. 2003;138:705-13.

89. Winston DJ, Bartoni K, Territo MC, et al. Efficacy and safety and breakthrough infections associated with standard long-term posaconazole antifungal prophylaxis in allogeneic stem cell transplant recipients. Biol Blood Marrow Transplant. 2011;17:507-15.

90. Thompson 3rd GR, Rinaldi MG, Pennick G, et al. Posaconazole therapeutic drug monitoring: a reference laboratory experience. Antimicrob Agents Chemother. 2009;53:2223-4.

91. Miyakis S, van Hal SJ, Ray J, et al. Voriconazole concentrations and outcome of invasive fungal infections. Clin Microbiol Infect. 2010;16:927-33. 
92. Pascual A, Calandra T, Bolay S, Buclin T, Bille J, Marchetti O. Voriconazole therapeutic drug monitoring in patients with invasive mycoses improves efficacy and safety outcomes. Clin Infect Dis. 2008;46:201-11.

93. Vehreschild JJ, Bohme A, Buchheidt D, Arenz D, Harnischmacher U, Heussel CP, Ullmann AJ, Mousset S, Hummel M, Frommolt P, Wassmer G, Drzisga I, Cornely OA. A double-blind trial on prophylactic voriconazole (VRC) or placebo during induction chemotherapy for acute myelogenous leukaemia (AML). J Infect. 2007;55:445-9.

94. Trifilio S, Verma A, Mehta J. Antimicrobial prophylaxis in hematopoietic stem cell transplant recipients: heterogeneity of current clinical practice. Bone Marrow Transplant. 2004;33:735-9.

95. Grow WB, Moreb JS, Roque D, Manion K, Leather H, Reddy V, Khan SA, Finiewicz KJ, Nguyen H, Clancy CJ, Mehta PS, Wingard JR. Late onset of invasive aspergillus infection in bone marrow transplant patients at a university hospital. Bone Marrow Transplant. 2002;29:15-9.

96. Wingard J, Carter CL, Walsh TJ, et al. Results of a randomized, double-blind trial of fluconazole vs. voriconazole for the prevention of invasive fungal infections allogenic blood and marrow transplant (BMT) patients. Blood. 2010;116:5111-8.

97. Marks DI, Kibbler C, Pagliuca A, et al. Voriconazole (VOR) vs itraconazole (ITR) for primary prophylaxis of invasive fungal infection (IFI) in allogeneic hematopoietic cell transplant (HCT) recipients [abstract M-1249a]. In: 49th Interscience conference on antimicrobial agents and chemotherapy. San Francisco, CA; 2009.

98. Bjerke J, Meyer JD, Bowden RA. Hepatosplenic candidiasis-a contraindication to marrow transplantation? Blood. 1994;84: 2811-4.

99. Offner F, Cordonnier C, Ljungman P, Prentice HG, Engelhard D, De Bacquer D, Meunier F, De Pauw B. Impact of previous aspergillosis on the outcome of bone marrow transplantation. Clin Infect Dis. 1998;26:1098-103.

100. Fukuda T, Boeckh M, Gutherie MA, Mattson DK, Owens S, Wald A, Sandmaier BM, Corey L, Storb RF, Marr KA. Invasive aspergillosis before allogeneic HSCT: 10 year single center experience. Biol Blood Marrow Transplant. 2004;10:494-503.

101. deFabritiis P, Spagnoli A, DiBartolomeo G, Locasciulli A, Cudillo L, Milone G, Busca A, Picardi A, Scimè R, Bonini A, Cupelli L, Chiusolo P, Olivieri A, Santarone S, Poidomani M, Fallani S, Novelli A, Majolino I. Efficacy of caspofungin as secondary prophylaxis in patients undergoing allogeneic stem cell transplantation with prior history of pulmonary and/or systemic fungal infection. Bone Marrow Transplant. 2007;40:245-9.

102. Cordonnier C, Maury S, Pautas C, Bastié JN, Chehata S, Castaigne S, Kuentz M, Bretagne S, Ribaud P. Secondary antifungal prophylaxis with voriconazole to adhere to scheduled treatment in leukemic patients and stem cell transplant recipients. Bone Marrow Transplant. 2004;33:943-8.

103. Mermel LA, Maki DG. Detection of bacteremia in adults: consequences of culturing an inadequate volume of blood. Ann Intern Med. 1993;119:270-2.

104. Lee A, Mirrett S, Reller LB, Weinstein MP. Detection of bloodstream infections in adults: how many blood cultures are needed? J Clin Microbiol. 2007;45:3546-8.

105. Cockerill 3rd FR, Wilson JW, Vetter EA, Goodman KM, Torgerson CA, Harmsen WS, Schleck CD, Ilstrup DM, Washington 2nd JA, Wilson WR. Optimal testing parameters for blood cultures. Clin Infect Dis. 2004;38:1724-30.

106. DesJardin JA, Falagas ME, Ruthazer R, Griffith J, Wawrose D, Schenkein D, Miller K, Snydman DR. Clinical utility of blood cultures drawn from indwelling central venous catheters in hospitalized patients with cancer. Ann Intern Med. 1999;131:641-7.

107. Weinstein MP. Current blood culture methods and systems: clinical concepts, technology, and interpretation of results. Clin Infect Dis. 1996;23:40-6.
108. Stevens DL, Bisno AL, Chambers HF, Everett ED, Dellinger P, Goldstein EJ, Gorbach SL, Hirschmann JV, Kaplan EL, Montoya JG, Wade JC, Infectious Diseases Society of America. Clinical practice guidelines for the diagnosis and management of skin and soft tissue infections, IDSA. Clin Infect Dis. 2005;41:1373-406.

109. Freifeld A, Marchigiani D, Walsh T, Chanock S, Lewis L, Hiemenz J, Hiemenz S, Hicks JE, Gill V, Steinberg SM, Pizzo PA. A double-blind comparison of empirical oral and intravenous antibiotic therapy for low-risk febrile patients with neutropenia during cancer chemotherapy. N Engl J Med. 1999;341:305-11.

110. Kern WV, Cometta A, De Bock R, Langenaeken J, Paesmans M, Gaya H. Oral versus intravenous empirical antimicrobial therapy for fever in patients with granulocytopenia who are receiving cancer chemotherapy. International Antimicrobial Therapy Cooperative Group of the European Organization for Research and Treatment of Cancer. N Engl J Med. 1999;341:312-8.

111. Malik IA, Khan WA, Karim M, Aziz Z, Khan MA. Feasibility of outpatient management of fever in cancer patients with low-risk neutropenia: results of a prospective randomized trial. Am J Med. 1995;98:224-31.

112. Rolston KV, Manzullo EF, Elting LS, Frisbee-Hume SE, McMahon L, Theriault RL, Patel S, Benjamin RS. Once daily, oral, outpatient quinolone monotherapy for low-risk cancer patients with fever and neutropenia: a pilot study of 40 patients based on validated risk-prediction rules. Cancer. 2006;106:2489-94.

113. Innes HE, Smith DB, O'Reilly SM, Clark PI, Kelly V, Marshall E. Oral antibiotics with early hospital discharge compared with inpatient intravenous antibiotics for low-risk febrile neutropenia in patients with cancer: a prospective randomised controlled single centre study. Br J Cancer. 2003;89:43-9.

114. Kamana M, Escalante C, Mullen CA, Frisbee-Hume S, Rolston $\mathrm{KV}$. Bacterial infections in low-risk, febrile neutropenic patients. Cancer. 2005; 104:422-6.

115. Klastersky J, Paesmans M, Georgala A, Muanza F, Plehiers B, Dubreucq L, Lalami Y, Aoun M, Barette M. Outpatient oral antibiotics for febrile neutropenic cancer patients using a score predictive for complications. J Clin Oncol. 2006;24:4129-34.

116. Kern WV. Risk assessment and treatment of low-risk patients with febrile neutropenia. Clin Infect Dis. 2006;42:533-40.

117. Talcott JA, Finberg R, Mayer RJ, Goldman L. The medical course of cancer patients with fever and neutropenia. Clinical identification of a low-risk subgroup at presentation. Arch Intern Med. 1988;148:2561-8.

118. Klastersky J, Ameye L, Maertens J, Georgala A, Muanza F, Aoun M, Ferrant A, Rapoport B, Rolston K, Paesmans M. Bacteraemia in febrile neutropenic cancer patients. Int J Antimicrob Agents. 2007;30 Suppl 1:S51-9.

119. Lodise Jr TP, Patel N, Kwa A, Graves J, Furuno JP, Graffunder E, Lomaestro B, McGregor JC. Predictors of 30-day mortality among patients with Pseudomonas aeruginosa bloodstream infections: impact of delayed appropriate antibiotic selection. Antimicrob Agents Chemother. 2007;51:3510-5.

120. Ramphal R. Changes in the etiology of bacteremia in febrile neutropenic patients and the susceptibilities of the currently isolated pathogens. Clin Infect Dis. 2004;39 Suppl 1:S25-31.

121. Spanik S, Krupova I, Trupl J, Kunová A, Novotny J, Mateicka F, Pichnova E, Sulcova M, Sabo A, Jurga L, Krcmery Jr V. Bacteremia due to multiresistant gram-negative bacilli in neutropenic cancer patients: a case-controlled study. J Infect Chemother. 1999;5:180-4.

122. Falcone M, Micozzi A, Pompeo ME, Baiocchi P, Fabi F, Penni A, Martino P, Venditti M. Methicillin-resistant staphylococcal bacteremia in patients with hematologic malignancies: clinical and microbiological retrospective comparative analysis of $S$. haemolyticus, S. epidermidis and S. aureus. J Chemother. 2004;16:540-8.

123. Paul M, Soares-Weiser K, Grozinsky S, Leibovici L. Beta-lactam versus beta-lactam-aminoglycoside combination therapy in cancer patients with neutropaenia. Cochrane Database Syst Rev 2002; CD003038. 
124. Paterson DL, Ko WC, Von Gottberg A, Casellas JM, Mulazimoglu L, Klugman KP, Bonomo RA, Rice LB, McCormack JG, Yu VL. Outcome of cephalosporin treatment for serious infections due to apparently susceptible organisms producing extended-spectrum beta-lactamases: implications for the clinical microbiology laboratory. J Clin Microbiol. 2001;39:2206-12.

125. Fritsche TR, Sader HS, Jones RN. Comparative activity and spectrum of broad-spectrum beta-lactams (cefepime, ceftazidime, ceftriaxone, piperacillin/tazobactam) tested against 12,295 staphylococci and streptococci: report from the SENTRY antimicrobial surveillance program (North America: 2001-2002). Diagn Microbiol Infect Dis. 2003;47:435-40.

126. Johnson PR, Yin JA, Tooth JA. High dose intravenous ciprofloxacin in febrile neutropenic patients. $J$ Antimicrob Chemother. 1990;26(Suppl F):101-7.

127. Meunier F, Zinner SH, Gaya H, Calandra T, Viscoli C, Klastersky J, Glauser M. Prospective randomized evaluation of ciprofloxacin versus piperacillin plus amikacin for empiric antibiotic therapy of febrile granulocytopenic cancer patients with lymphomas and solid tumors. The European Organization for Research on Treatment of Cancer International Antimicrobial Therapy Cooperative Group. Antimicrob Agents Chemother. 1991;35:873-8.

128. Bodey GP, Fainstein V, Elting LS, Anaissie E, Rolston K, Khardori N, Kantarjian H, Plager C, Murphy WK, Holmes F, et al. Betalactam regimens for the febrile neutropenic patient. Cancer. 1990;65:9-16.

129. Anaissie EJ, Fainstein V, Bodey GP, Rolston K, Elting L, Kantarjian H, Cabanillas F, McCredie KB. Randomized trial of beta-lactam regimens in febrile neutropenic cancer patients. Am J Med. 1988;84:581-9.

130. Yahav D, Paul M, Fraser A, Sarid N, Leibovici L. Efficacy and safety of cefepime: a systematic review and meta-analysis. Lancet Infect Dis. 2007;7:338-48.

131. Kang CI, Kim SH, Park WB, Lee KD, Kim HB, Kim EC, Oh MD, Choe KW. Bloodstream infections due to extended-spectrum betalactamase-producing Escherichia coli and Klebsiella pneumoniae: risk factors for mortality and treatment outcome, with special emphasis on antimicrobial therapy. Antimicrob Agents Chemother. 2004;48:4574-81.

132. Aubron C, Poirel L, Fortineau N, Nicolas P, Collet L, Nordmann P. Nosocomial spread of Pseudomonas aeruginosa isolates expressing the metallo-beta-lactamase VIM-2 in a hematology unit of a French hospital. Microb Drug Resist. 2005;11:254-9.

133. Paul M, Borok S, Fraser A, Vidal L, Leibovici L. Empirical antibiotics against Gram-positive infections for febrile neutropenia: systematic review and meta-analysis of randomized controlled trials. J Antimicrob Chemother. 2005;55:436-44.

134. Wade JC, Glasmacher A. Vancomycin does not benefit persistently febrile neutropenic people with cancer. Cancer Treat Rev. 2004;30:119-26.

135. DiazGranados CA, Jernigan JA. Impact of vancomycin resistance on mortality among patients with neutropenia and enterococcal bloodstream infection. J Infect Dis. 2005;191:588-95.

136. Koc Y, Snydman DR, Schenkein DS, Miller KB. Vancomycinresistant enterococcal infections in bone marrow transplant recipients. Bone Marrow Transplant. 1998;22:207-9.

137. Vergis EN, Hayden MK, Chow JW, Snydman DR, Zervos MJ, Linden PK, Wagener MM, Schmitt B, Muder RR. Determinants of vancomycin resistance and mortality rates in enterococcal bacteremia. a prospective multicenter study. Ann Intern Med. 2001;135:484-92.

138. Cunha BA. Antimicrobial therapy of multidrug-resistant Streptococcus pneumoniae, vancomycin-resistant enterococci, and methicillin-resistant Staphylococcus aureus. Med Clin North Am. 2006;90:1165-82.

139. Whitener CJ, Park SY, Browne FA, Parent LJ, Julian K, Bozdogan B, Appelbaum PC, Chaitram J, Weigel LM, Jernigan J, McDougal
LK, TenoverFC, Fridkin SK. Vancomycin-resistant Staphylococcus aureus in the absence of vancomycin exposure. Clin Infect Dis. 2004;38:1049-55.

140. Ghanem GA, Boktour M, Warneke C, Pham-Williams T, Kassis C, Bahna P, Aboufaycal H, Hachem R, Raad I. Catheter-related Staphylococcus aureus bacteremia in cancer patients: high rate of complications with therapeutic implications. Medicine(Baltimore). 2007;86:54-60.

141. Razonable RR, Litzow MR, Khaliq Y, Piper KE, Rouse MS, Patel R. Bacteremia due to viridans group Streptococci with diminished susceptibility to levofloxacin among neutropenic patients receiving levofloxacin prophylaxis. Clin Infect Dis. 2002;34:1469-74.

142. Rice LB. Antimicrobial resistance in gram-positive bacteria. Am J Infect Control. 2006;34:S11-9; discussion S64-73.

143. Bruckner L, Gigliotti F. Viridans group streptococcal infections among children with cancer and the importance of emerging antibiotic resistance. Semin Pediatr Infect Dis. 2006;17:153-60.

144. Gruson D, Hilbert G, Pigneux A, Vargas F, Guisset O, Texier J, Boiron JM, Reiffers J, Gbikpi-Benissan G, Cardinaud JP. Severe infection caused by Stomatococcus mucilaginosus in a neutropenic patient: case report and review of the literature. Hematol Cell Ther. 1998;40:167-9.

145. Kumashi P, Girgawy E, Tarrand JJ, Rolston KV, Raad II, Safdar A. Streptococcus pneumoniae bacteremia in patients with cancer: disease characteristics and outcomes in the era of escalating drug resistance (1998-2002). Medicine (Baltimore). 2005;84:303-12.

146. Aksoy DY, Unal S. New antimicrobial agents for the treatment of Gram-positive bacterial infections. Clin Microbiol Infect. 2008; $14: 411-20$.

147. Mehta S, Johnson J, Venezia R, Forrest G. Emergence of linezolid-resistant enterococci in a neutropenic patient. J Hosp Infect. 2006;62:125-7.

148. Verma N, Clarke RW, Bolton-Maggs PH, van Saene HK. Gut overgrowth of vancomycin-resistant enterococci (VRE) results in linezolid-resistant mutation in a child with severe congenital neutropenia: a case report. J Pediatr Hematol Oncol. 2007;29: $557-60$

149. Jaksic B, Martinelli G, Perez-Oteyza J, Hartman CS, Leonard LB, Tack KJ. Efficacy and safety of linezolid compared with vancomycin in a randomized, double-blind study of febrile neutropenic patients with cancer. Clin Infect Dis. 2006;42:597-607.

150. Faguer S, Kamar N, Fillola G, Guitard J, Rostaing L. Linezolidrelated pancytopenia in organ-transplant patients: report of two cases. Infection. 2007;35:275-7.

151. Kollef MH. Inadequate antimicrobial treatment: an important determinant of outcome for hospitalized patients. Clin Infect Dis. 2000;31 Suppl 4:S131-8.

152. Wang FD, Liu CY, Hsu HC, Gau JP, Chau WK, Haung ML, Ho $\mathrm{CH}$. A comparative study of cefepime versus ceftazidime as empiric therapy of febrile episodes in neutropenic patients. Chemotherapy. 1999;45:370-9.

153. Paul M, Silbiger I, Grozinsky S, Soares-Weiser K, Leibovici L. Beta lactam antibiotic monotherapy versus beta lactam-aminoglycoside antibiotic combination therapy for sepsis. Cochrane Database Syst Rev 2006;CD003344.

154. Safdar N, Handelsman J, Maki DG. Does combination antimicrobial therapy reduce mortality in Gram-negative bacteraemia? A meta-analysis. Lancet Infect Dis. 2004;4:519-27.

155. Glasmacher A, von Lilienfeld-Toal M, Schulte S, Hahn C, Schmidt-Wolf IG, Prentice A. An evidence-based evaluation of important aspects of empirical antibiotic therapy in febrile neutropenic patients. Clin Microbiol Infect. 2005;11 Suppl 5:17-23.

156. No authors listed. Guidelines for the management of adults with hospital-acquired, ventilator-associated, and healthcare-associated pneumonia. Am J Respir Crit Care Med. 2005;171:388-416 
157. Cronin CG, O'Connor M, Lohan DG, Keane M, Roche C, Bruzzi JF, Murphy JM. Imaging of the gastrointestinal complications of systemic chemotherapy. Clin Radiol. 2009;64:724-33.

158. Gorschluter M, Mey U, Strehl J, Ziske C, Schepke M, SchmidtWolf IG, Sauerbruch T, Glasmacher A. Neutropenic enterocolitis in adults: systematic analysis of evidence quality. Eur J Haematol. 2005;75:1-13.

159. Mermel LA, Allon M, Bouza E, Craven DE, Flynn P, O'Grady NP, Raad II, Rijnders BJ, Sherertz RJ, Warren DK. Clinical practice guidelines for the diagnosis and management of intravascular catheter-related infection: 2009 Update by the Infectious Diseases Society of America. Clin Infect Dis. 2009;49:1-45.

160. Benoit JL, Carandang G, Sitrin M, Arnow PM. Intraluminal antibiotic treatment of central venous catheter infections in patients receiving parenteral nutrition at home. Clin Infect Dis. 1995;21:1286-8.

161. Johnson DC, Johnson FL, Goldman S. Preliminary results treating persistent central venous catheter infections with the antibiotic lock technique in pediatric patients. Pediatr Infect Dis J. 1994;13:930-1.

162. Safdar N, Fine JP, Maki DG. Meta-analysis: methods for diagnosing intravascular device-related bloodstream infection. Ann Intern Med. 2005;142:451-66.

163. Chatzinikolaou I, Hanna H, Hachem R, Alakech B, Tarrand J, Raad I. Differential quantitative blood cultures for the diagnosis of catheter-related bloodstream infections associated with short- and long-term catheters: a prospective study. Diagn Microbiol Infect Dis. 2004;50:167-72.

164. Seifert H, Cornely O, Seggewiss K, Decker M, Stefanik D, Wisplinghoff H, Fätkenheuer G. Bloodstream infection in neutropenic cancer patients related to short-term nontunnelled catheters determined by quantitative blood cultures, differential time to positivity, and molecular epidemiological typing with pulsed-field gel electrophoresis. J Clin Microbiol. 2003;41:118-23.

165. Raad I, Hanna HA, Alakech B, Chatzinikolaou I, Johnson MM, Tarrand J. Differential time to positivity: a useful method for diagnosing catheter-related bloodstream infections. Ann Intern Med. 2004; $140: 18-25$.

166. Elting LS, Lu C, Escalante CP, Giordano SH, Trent JC, Cooksley C, Avritscher EB, Shih YC, Ensor J, Bekele BN, Gralla RJ, Talcott JA, Rolston K. Outcomes and cost of outpatient or inpatient management of 712 patients with febrile neutropenia. J Clin Oncol. 2008;26:606-11.

167. Escalante CP, Weiser MA, Manzullo E, Benjamin R, Rivera E, Lam T, Ho V, Valdres R, Lee EL, Badrina N, Fernandez S, DeJesus Y, Rolston K. Outcomes of treatment pathways in outpatient treatment of low risk febrile neutropenic cancer patients. Support Care Cancer. 2004;12:657-62.

168. Elting LS, Rubenstein EB, Rolston K, Cantor SB, Martin CG, Kurtin D, Rodriguez S, Lam T, Kanesan K, Bodey G. Time to clinical response: an outcome of antibiotic therapy of febrile neutropenia with implications for quality and cost of care. J Clin Oncol. 2000;21:3699-706.

169. Freifeld AG, Walsh T, Marshall D, Gress J, Steinberg SM, Hathorn J, Rubin M, Jarosinski P, Gill V, Young RC, et al. Monotherapy for fever and neutropenia in cancer patients: a randomized comparison of ceftazidime versus imipenem. J Clin Oncol. 1995;13: $165-76$.

170. Antoniadou A, Giamarellou H. Fever of unknown origin in febrile leukopenia. Infect Dis Clin North Am. 2007;21:1055-90.

171. Pizzo PA. Approach to the patient with prolonged granulocytopenia. Recent Results Cancer Res. 1993;132:57-65.

172. Gill S, Carney D, Ritchie D, Wolf M, Westerman D, Prince HM, Januszewicz H, Seymour JF. The frequency, manifestations, and duration of prolonged cytopenias after first-line fludarabine combination chemotherapy. Ann Oncol. 2010;21:331-4.
173. Gerson SL, Talbot GH, Hurwitz S, Strom BL, Lusk EJ, Cassileth PA. Prolonged granulocytopenia: the major risk factor for invasive pulmonary aspergillosis in patients with acute leukemia. Ann Intern Med. 1984;100:345-51.

174. Portugal RD, Garnica M, Nucci M. Index to predict invasive mold infection in high-risk neutropenic patients based on the area over the neutrophil curve. J Clin Oncol. 2009;27:3849-54.

175. Pagano L, Caira M, Candoni A, Offidani M, Fianchi L, Martino B, Pastore D, Picardi M, Bonini A, Chierichini A, Fanci R, Caramatti C, Invernizzi R, Mattei D, Mitra ME, Melillo L, Aversa F, Van Lint MT, Falcucci P, Valentini CG, Girmenia C, Nosari A. The epidemiology of fungal infections in patients with hematologic malignancies: the SEIFEM-2004 study. Haematologica. 2006;91:1068-75.

176. Walsh TJ, Finberg R, Arndt C, et al. Liposomal amphotericin B is effective for empirical antifungal therapy in cancer patients with fever and neutropenia. N Engl J Med. 1999;340:764-71.

177. Walsh TJ, Finberg RW, Arndt C, Hiemenz J, Schwartz C, Bodensteiner D, Pappas P, Seibel N, Greenberg RN, Dummer S, Schuster M, Holcenberg JS. Liposomal amphotericin B for empirical therapy in patients with persistent fever and neutropenia. National Institute of Allergy and Infectious Diseases Mycoses Study Group. N Engl J Med. 1999;340:764-71.

178. Walsh TJ, Pappas P, Winston DJ, Lazarus HM, Petersen F, Raffalli J, Yanovich S, Stiff P, Greenberg R, Donowitz G, Schuster M, Reboli A, Wingard J, Arndt C, Reinhardt J, Hadley S, Finberg R, Laverdière M, Perfect J, Garber G, Fioritoni G, Anaissie E, Lee J, National Institute of Allergy and Infectious Diseases Mycoses Study Group. Voriconazole compared with liposomal amphotericin B for empirical antifungal therapy in patients with neutropenia and persistent fever. N Engl J Med. 2002;346:225-34.

179. Walsh TJ, Teppler H, Donowitz GR, Maertens JA, Baden LR, Dmoszynska A, Cornely OA, Bourque MR, Lupinacci RJ, Sable CA, dePauw BE. Caspofungin versus liposomal amphotericin B for empirical antifungal therapy in patients with persistent fever and neutropenia. N Engl J Med. 2004;351:1391-402.

180. Wingard JR, White MH, Anaissie E, Raffalli J, Goodman J, Arrieta A, L Amph/ABLC Collaborative Study Group. A randomized, double-blind comparative trial evaluating the safety of liposomal amphotericin B versus amphotericin B lipid complex in the empirical treatment of febrile neutropenia. LAmph/ABLC Collaborative Study Group. Clin Infect Dis. 2000;31:1155-63.

181. Trifilio S, Singhal S, Williams S, Frankfurt O, Gordon L, Evens A, Winter J, Tallman M, Pi J, Mehta J. Breakthrough fungal infections after allogeneic hematopoietic stem cell transplantation in patients on prophylactic voriconazole. Bone Marrow Transplant. 2007;40:451-6.

182. Krishna G, Martinho M, Chandrasekar P, Ullmann AJ, Patino H. Pharmacokinetics of oral posaconazole in allogeneic hematopoietic stem cell transplant recipients with graft-versus-host disease. Pharmacotherapy. 2007;27:1627-36.

183. Odabasi Z, Mattiuzzi G, Estey E, Kantarjian H, Saeki F, Ridge RJ, Ketchum PA, Finkelman MA, Rex JH, Ostrosky-Zeichner L. Beta-D-glucan as a diagnostic adjunct for invasive fungal infections: validation, cutoff development, and performance in patients with acute myelogenous leukemia and myelodysplastic syndrome. Clin Infect Dis. 2004;39:199-205.

184. Ostrosky-Zeichner L, Alexander BD, Kett DH, Kett DH, Vazquez J, Pappas PG, Saeki F, Ketchum PA, Wingard J, Schiff R, Tamura $\mathrm{H}$, Finkelman MA, Rex JH. Multicenter clinical evaluation of the $(1->3)$ beta-D-glucan assay as an aid to diagnosis of fungal infections in humans. Clin Infect Dis. 2005;41:654-9.

185. Senn L, Robinson JO, Schmidt S, Knaup M, Asahi N, Satomura S, Matsuura S, Duvoisin B, Bille J, Calandra T, Marchetti O. 1,3-Beta-D-glucan antigenemia for early diagnosis of invasive fungal infections in neutropenic patients with acute leukemia. Clin Infect Dis. 2008;46:878-85. 
186. Maertens J, Verhaegen J, Lagrou K, et al. Screening for circulating galactomannan as a noninvasive diagnostic tool for invasive aspergillosis in prolonged neutropenic patients and stem cell transplantation recipients: a prospective validation. Blood. 2001;97: 1604-10.

187. Marr KA, Balajee SA, McLaughlin L, Tabouret M, Bentsen C, Walsh TJ. Detection of galactomannan antigenemia by enzyme immunoassay for the diagnosis of invasive aspergillosis: variables that affect performance. J Infect Dis. 2004;190:641-9.

188. Marr KA, Laverdiere M, Gugel A, Leisenring W. Antifungal therapy decreases sensitivity of the Aspergillus galactomannan enzyme immunoassay. Clin Infect Dis. 2005;40:1762-9.

189. Caillot D, Casasnovas O, Bernard A, Couaillier JF, Durand C, Cuisenier B, Solary E, Piard F, Petrella T, Bonnin A, Couillault G, Dumas M, Guy H. Improved management of invasive pulmonary aspergillosis in neutropenic patients using early thoracic computed tomographic scan and surgery. J Clin Oncol. 1997;15:139-47.

190. Greene RE, Schlamm HT, Oestmann JW, Stark P, Durand C, Lortholary O, Wingard JR, Herbrecht R, Ribaud P, Patterson TF, Troke PF, Denning DW, Bennett JE, de Pauw BE, Rubin RH. Imaging findings in acute invasive pulmonary aspergillosis: clinical significance of the halo sign. Clin Infect Dis. 2007;44:373-9.

191. Kuhlman JE, Fishman EK, Siegelman SS. Invasive pulmonary aspergillosis in acute leukemia: characteristic findings on CT, the CT halo sign, and the role of CT in early diagnosis. Radiology. 1985;157:611-4.

192. de Pauw BE, Rubin RH. Empiric versus preemptive therapy in the management of febrile neutropenia in the patient being treated for hematologic malignancy. Transpl Infect Dis. 2006;8:1-2.

193. Maertens J, Theunissen K, Verhoef G, Verschakelen J, Lagrou K, Verbeken E, Wilmer A, Verhaegen J, Boogaerts M, Van Eldere J. Galactomannan and computed tomography-based preemptive antifungal therapy in neutropenic patients at high risk for invasive fungal infection: a prospective feasibility study. Clin Infect Dis. 2005;41:1242-50.

194. Cordonnier C, Pautas C, Maury S, Vekhoff A, Farhat H, Suarez F, Dhédin N, Isnard F, Ades L, Kuhnowski F, Foulet F, Kuentz M, Maison P, Bretagne S, Schwarzinger M. Empirical versus preemptive antifungal therapy for high-risk, febrile, neutropenic patients: a randomized, controlled trial. Clin Infect Dis. 2009;48:1042-51.

195. Hebart H, Klingspor L, Klingebiel T, Loeffler J, Tollemar J, Ljungman P, Wandt H, Schaefer-Eckart K, Dornbusch HJ, Meisner C, Engel C, Stenger N, Mayer T, Ringden O, Einsele H. A prospective randomized controlled trial comparing PCR-based and empirical treatment with liposomal amphotericin B in patients after allo-SCT. Bone Marrow Transplant. 2009;43:553-61.

196. Marr KA, Leisenring W, Bow E. Empirical versus preemptive antifungal therapy for fever during neutropenia. Clin Infect Dis. 2009;49:1138-9; author reply 39-40.

197. Aguilar-Guisado M, Espigado I, Cordero E, et al. Empirical antifungal therapy in selected patients with persistent febrile neutropenia. Bone Marrow Transplant. 2009;45:159-64.

198. de Pauw BE, Donnelly JP. Timely intervention for invasive fungal disease: should the road now lead to the laboratory instead of the pharmacy? Clin Infect Dis. 2009;48:1052-4.

199. Weisser M, Rausch C, Droll A, Simcock M, Sendi P, Steffen I, Buitrago C, Sonnet S, Gratwohl A, Passweg J, Fluckiger U. Galactomannan does not precede major signs on a pulmonary computerized tomographic scan suggestive of invasive aspergillosis in patients with hematological malignancies. Clin Infect Dis. 2005;41:1143-9.

200. Gil L, Styczynski J, Komarnicki M. Infectious complication in 314 patients after high-dose therapy and autologous hematopoietic stem cell transplantation: risk factors analysis and outcome. Infection. 2007;35:421-7.
201. Nucci M, Marr KA, Queiroz-Telles F, Martins CA, Trabasso P, Costa S, Voltarelli JC, Colombo AL, Imhof A, Pasquini R, Maiolino A, Souza CA, Anaissie E. Fusarium infection in hematopoietic stem cell transplant recipients. Clin Infect Dis. 2004:38:1237-42.

202. Anaissie E, Stratton S, Summerbell R, et al. Opportunistic moulds in a hospital water system: a 3-year prospective study (abstract). Blood. 2000;96:787.

203. Pfeiffer CD, Fine JP, Safdar N. Diagnosis of invasive aspergillosis using a galactomannan assay: a meta-analysis. Clin Infect Dis. 2006;42:1417-727.

204. Maertens J, Van Eldere J, Verhaegen J, Verbeken E, Verschakelen $\mathrm{J}$, Boogaerts $\mathrm{M}$. Use of circulating galactomannan screening for early diagnosis of invasive aspergillosis in allogeneic stem cell transplant recipients. J Infect Dis. 2002;186:1297-306.

205. Herbrecht R, Letscher-Bru V, Oprea C, Lioure B, Waller J, Campos F, Villard O, Liu KL, Natarajan-Amé S, Lutz P, Dufour P, Bergerat JP, Candolfi E. Aspergillus galactomannan detection in the diagnosis of invasive aspergillosis in cancer patients. J Clin Oncol. 2002;20:1898-906.

206. Viscoli C, Girmenia A, Marinus A, Collette L, Martino P, Vandercam B, Doyen C, Lebeau B, Spence D, Krcmery V, De Pauw B, Meunier F. Candidemia in cancer patients: a prospective multicenter surveillance study by the Invasive Fungal Infection Group (IFIG) to the European Organization for the Research and Treatment of Cancer (EORTC). Clin Infect Dis. 1999;28:1071-9.

207. Infectious Diseases Society of America. Clinical practice guidelines for the management of candidiasis; 2009 update by the infectious diseases society of America. Clin Infect Dis. 2009;48:503-35.

208. Kullberg BJ, Sobel JD, Ruhnke M, Pappas PG, Viscoli C, Rex JH, Cleary JD, Rubinstein E, Church LW, Brown JM, Schlamm HT, Oborska IT, Hilton F, Hodges MR. Voriconazole versus a regimen of amphotericin B followed by fluconazole for candidaemia in non-neutropenic patients: a randomised non-inferiority trial. Lancet. 2005;366:1435-42.

209. Walsh TJ. Echinocandins - an advance in the primary treatment of invasive candidiasis. N Engl J Med. 2002;347:2070-2.

210. Krause DS, Simjee AE, van Rensburg C, Viljoen J, Walsh TJ, Goldstein BP, Wible M, Henkel T. A randomized, double- blind trial of anidulafungin versus fluconazole for the treatment of esophageal candidiasis. Clin Infect Dis. 2004;39:770-5.

211. Mora-Duarte J, Betts R, Rotstein C, et al. Comparison of caspofungin and amphotericin B for invasive candidiasis. N Engl J Med. 2002;347:2020-9.

212. Kuse ER, Chetchotisakd P, da Cunha CA, Ruhnke M, Barrios C, Raghunadharao D, Sekhon JS, Freire A, Ramasubramanian V, Demeyer I, Nucci M, Leelarasamee A, Jacobs F, Decruyenaere J, Pittet D, Ullmann AJ, Ostrosky-Zeichner L, Lortholary O, Koblinger S, Diekmann-Berndt H, Cornely OA, Micafungin Invasive Candidiasis Working Group. Micafungin versus liposomal amphotericin B for candidaemia and invasive candidosis: a phase III randomised double-blind trial. Lancet. 2007;369:1519-27.

213. Reboli AC, Rotstein C, Pappas PG, Chapman SW, Kett DH, Kumar D, Betts R, Wible M, Goldstein BP, Schranz J, Krause DS, Walsh TJ, Anidulafungin Study Group. Anidulafungin versus fluconazole for invasive candidiasis. $N$ Engl $\mathrm{J}$ Med. 2007;356:2472-82.

214. Pappas PG, Rotstein CM, Betts RF, Nucci M, Talwar D, De Waele JJ, Vazquez JA, Dupont BF, Horn DL, Ostrosky-Zeichner L, Reboli AC, Suh B, Digumarti R, Wu C, Kovanda LL, Arnold LJ, Buell DN. Micafungin versus caspofungin for treatment of candidemia and other forms of invasive candidiasis. Clin Infect Dis. 2007;45:883-93.

215. Anaissie EJ, Rex JH, Uzun O, Vartivarian S. Predictors of adverse outcome in cancer patients with candidemia. Am J Med. 1998;104:238-45. 
216. Denning DW, Marinus A, Cohen J, Spence D, Herbrecht R, Pagano L, Kibbler C, Kcrmery V, Offner F, Cordonnier C, Jehn U, Ellis M, Collette L, Sylvester R. An EORTC multicentre prospective survey of invasive aspergillosis in haematological patients: diagnosis and therapeutic outcome (EORTC Invasive Fungal Infections Cooperative Group). J Infect. 1998;37:173-80.

217. Lin SJ, Schranz J, Teutsch SM. Aspergillosis case-fatality rate: systematic review of the literature. Clin Infect Dis. 2001;32:358-66.

218. Guo YL, Chen YQ, Wang K, Qin SM, Wu C, Kong JL. Accuracy of BAL galactomannan in diagnosing invasive aspergillosis: a bivariate metaanalysis and systematic review. Chest. 2010;138(4):817-24.

219. Clancy CJ, Jaber RA, Leather HL, Wingard JR, Staley B, Wheat LJ, Cline CL, Rand KH, Schain D, Baz M, Nguyen MH. Bronchoalveolar lavage galactomannan in diagnosis of invasive pulmonary aspergillosis among solid-organ transplant recipients. J Clin Microbiol. 2007;45:1759-65.

220. Meersseman W, Lagrou K, Maertens J, et al. Galactomannan in bronchoalveolar lavage fluid: a tool for diagnosing aspergillosis in intensive care unit patients. Am J Respir Crit Care Med. 2008;177:27-34.

221. Hope WW, Walsh TJ, Denning DW. Laboratory diagnosis of invasive aspergillosis. Lancet Infect Dis. 2005;5:609-22.

222. Walsh TJ, Anaissie EJ, Denning DW, Herbrecht R, Kontoyiannis DP, Marr KA, Morrison VA, Segal BH, Steinbach WJ, Stevens DA, van Burik JA, Wingard JR, Patterson TF, Infectious Diseases Society of America. Treatment of aspergillosis: clinical practice guidelines of the infectious diseases society of America. Clin Infect Dis. 2008;46:327-60.

223. Herbrecht R, Denning DW, Patterson TF, Bennett JE, Greene RE, Oestmann JW, Kern WV, Marr KA, Ribaud P, Lortholary O, Sylvester R, Rubin RH, Wingard JR, Stark P, Durand C, Caillot D, Thiel E, Chandrasekar PH, Hodges MR, Schlamm HT, Troke PF, de Pauw B, Invasive Fungal Infections Group of the European Organisation for Research and Treatment of Cancer and the Global Aspergillus Study Group. Voriconazole versus amphotericin B for primary therapy of invasive aspergillosis. $N$ Engl J Med. 2002;347:408-15.

224. Maertens J, Raad I, Petrikkos G, Boogaerts M, Selleslag D, Petersen FB, Sable CA, Kartsonis NA, Ngai A, Taylor A, Patterson TF, Denning DW, Walsh TJ, Caspofungin Salvage Aspergillosis Study Group. Efficacy and safety of caspofungin for treatment of invasive aspergillosis in patients refractory to or intolerant of conventional antifungal therapy. Clin Infect Dis. 2004;39:1563-71.

225. Kirkpatrick WR, Perea S, Coco BJ, Patterson TF. Efficacy of caspofungin alone and in combination with voriconazole in a Guinea pig model of invasive aspergillosis. Antimicrob Agents Chemother. 2002;46:2564-8.

226. Petraitis V, Petraitiene R, Sarafandi AA, Kelaher AM, Lyman CA, Casler HE, Sein T, Groll AH, Bacher J, Avila NA, Walsh TJ. Combination therapy in treatment of experimental pulmonary aspergillosis: synergistic interaction between an antifungal triazole and an echinocandin. J Infect Dis. 2003;187:1834-43.

227. Greenberg RN, Mullane K, van Burik JA, Raad I, Abzug MJ, Anstead G, Herbrecht R, Langston A, Marr KA, Schiller G, Schuster M, Wingard JR, Gonzalez CE, Revankar SG, Corcoran G, Kryscio RJ, Hare R. Posaconazole as salvage therapy for zygomycosis. Antimicrob Agents Chemother. 2006;50:126-33.

228. Pitisuttithum P, Negroni R, Graybill JR, Bustamante B, Pappas P, Chapman S, Hare RS, Hardalo CJ. Activity of posaconazole in the treatment of central nervous system infections. J Antimicrob Chemother. 2005;56:745-55.

229. Raad II, Hachem RY, Herbrecht R, Graybill JR, Hare R, Corcoran G, Kontoyiannis DP. Posaconazole as salvage treatment for invasive fusariosis in patients with underlying hematologic malignancy and other conditions. Clin Infect Dis. 2006;42:1398-403.
230. Walsh TJ, Raad I, Patterson TF, Chandrasekar P, Donowitz GR, Graybill R, Greene RE, Hachem R, Hadley S, Herbrecht R, Langston A, Louie A, Ribaud P, Segal BH, Stevens DA, van Burik JA, White CS, Corcoran G, Gogate J, Krishna G, Pedicone L, Hardalo C, Perfect JR. Treatment of invasive aspergillosis with posaconazole in patients who are refractory to or intolerant of conventional therapy: an externally controlled trial. Clin Infect Dis. 2007;44(1):2-12.

231. Theodore S, Liava'a M, Antippa P, Wynne R, Grigg A, Slavin M, Tatoulis J. Surgical management of invasive pulmonary fungal infection in hematology patients. Ann Thorac Surg. 2009;87:1532-8.

232. Schwartz S, Ruhnke M, Ribaud P, Corey L, Driscoll T, Cornely OA, Schuler U, Lutsar I, Troke P, Thiel E. Improved outcome in central nervous system aspergillosis, using voriconazole treatment. Blood. 2005;106:2641-5.

233. Kontoyiannis DP, Wessel VC, Bodey GP, Rolston KV.Zygomycosis in the 1990 s in a tertiary-care cancer center. Clin Infect Dis. 2000;30:851-6.

234. Imhof A, Balajee SA, Fredricks DN, Englund JA, Marr KA. Breakthrough fungal infections in stem cell transplant recipients receiving voriconazole. Clin Infect Dis. 2004;39:743-6.

235. Marty FM, Cosimi LA, Baden LR. Breakthrough zygomycosis after voriconazole treatment in recipients of hematopoietic stemcell transplants. N Engl J Med. 2004;350(9):950-2.

236. van Burik JA, Hare RS, Solomon HF, Corrado ML, Kontoyiannis DP. Posaconazole is effective as salvage therapy in zygomycosis: a retrospective summary of 91 cases. Clin Infect Dis. 2006;42(7):e61-5; erratum in: Clin Infect Dis 2006;43(10):1376.

237. Marr KA, Boeckh M, Carter RA, Kim HW, Corey L. Combination antifungal therapy for invasive aspergillosis. Clin Infect Dis. 2004;39:797-802.

238. Maertens J, Glasmacher A, Herbrecht R, Thiebaut A, Cordonnier C, Segal BH, Killar J, Taylor A, Kartsonis N, Patterson TF, Aoun M, Caillot D, Sable C, Caspofungin Combination Therapy Study Group. Multicenter, noncomparative study of caspofungin in combination with other antifungals as salvage therapy in adults with invasive aspergillosis. Cancer. 2006;107:2888-97.

239. Denning DW, Marr KA, Lau WM, Facklam DP, Ratanatharathorn V, Becker C, Ullmann AJ, Seibel NL, Flynn PM, van Burik JA, Buell DN, Patterson TF. Micafungin (FK463), alone or in combination with other systemic antifungal agents, for the treatment of acute invasive aspergillosis. J Infect. 2006;53(5):337-49.

240. Cornely OA, Maertens J, Bresnik M, Ebrahimi R, Ullmann AJ, Bouza E, Heussel CP, Lortholary O, Rieger C, Boehme A, Aoun M, Horst HA, Thiebaut A, Ruhnke M, Reichert D, Vianelli N, Krause SW, Olavarria E, Herbrecht R, AmBiLoad Trial Study Group. Liposomal amphotericin B as initial therapy for invasive mold infection: a randomized trial comparing a high-loading dose regimen with standard dosing. Clin Infect Dis. 2007;44:1289-97.

241. Smith J, Safdar N, Knasinski V, Simmons W, Bhavnani SM, Ambrose PG, Andes D. Voriconazole therapeutic drug monitoring. Antimicrob Agents Chemother. 2006;50(4):1570-2.

242. Trifilio S, Pennick G, Pi J, et al. Monitoring plasma voriconazole levels may be necessary to avoid subtherapeutic levels in hematopoietic stem cell transplant recipients. Cancer. 2007;109(8):1532-5.

243. Marty FM, Lowry Cm, Cutler CS, Campbell BJ, Fiumara K, Baden LR, Antin JH. Voriconazole and sirolimus co-administration after allogeneic hematopoietic stem cell transplantation. Biol Blood Marrow Transplant. 2006;12:552-9.

244. Kuderer NM, Dale DC, Crawford J, et al. Impact of primary prophylaxis with granulocyte colony-stimulating factor on febrile neutropenia and mortality in adult cancer patients receiving chemotherapy: a systematic review. J Clin Oncol. 2007;25:3158-67.

245. Pinto L, Liu Z, Doan Q, Bernal M, Dubois R, Lyman G. Comparison of pegfilgrastim with filgrastim on febrile neutropenia, grade IV neutropenia and bone pain: a meta-analysis of randomized controlled trials. Curr Med Res Opin. 2007;23:2283-95. 
246. Aapro MS, Cameron DA, Pettengell R, Bohlius J, Crawford J, Ellis M, Kearney N, Lyman GH, Tjan-Heijnen VC, Walewski J, Weber DC, Zielinski C, European Organisation for Research and Treatment of Cancer (EORTC) Granulocyte Colony-Stimulating Factor (G-CSF) Guidelines Working Party. EORTC guidelines for the use of granulocyte-colony stimulating factor to reduce the incidence of chemotherapy-induced febrile neutropenia in adult patients with lymphomas and solid tumours. Eur J Cancer. 2006;42:2433-53.

247. Smith TJ, Khatcheressian J, Lyman GH, Ozer H, Armitage JO, Balducci L, Bennett CL, Cantor SB, Crawford J, Cross SJ, Demetri G, Desch CE, Pizzo PA, Schiffer CA, Schwartzberg L, Somerfield MR, Somlo G, Wade JC, Wade JL, Winn RJ, Wozniak AJ, Wolff AC. 2006 update of recommendations for the use of white blood cell growth factors: an evidence-based clinical practice guideline. J Clin Oncol. 2006;24:3187-205.

248. NCCN. Myeloid Growth Factors: NCCN Practice Guidelines 2009; v.1.2009.

249. Timmer-Bonte JN, Adang EM, Smit HJ, Biesma B, Wilschut FA, Bootsma GP, de Boo TM, Tjan-Heijnen VC. Cost-effectiveness of adding granulocyte colony-stimulating factor to primary prophylaxis with antibiotics in small-cell lung cancer. J Clin Oncol. 2006;24:2991-7.

250. Timmer-Bonte JN, Adang EM, Termeer E, Severens JL, TjanHeijnen VC. Modeling the cost effectiveness of secondary febrile neutropenia prophylaxis during standard-dose chemotherapy. J Clin Oncol. 2008;26:290-6.

251. Adams JR, Angelotta C, Bennett CL. When the risk of febrile neutropenia is $20 \%$, prophylactic colony-stimulating factor use is clinically effective, but is it cost-effective? J Clin Oncol. 2006;24:2975-7.
252. Kuderer NM, Dale DC, Crawford J, Cosler LE, Lyman GH. Mortality, morbidity, and cost associated with febrile neutropenia in adult cancer patients. Cancer. 2006;158:2258-66.

253. Wingard JR, Elmongy M. Strategies for minimizing complications of neutropenia: prophylactic myeloid growth factors or antibiotics. Crit Rev Oncol Hematol. 2009;72:144-54.

254. Lyman GH, Shayne M. Granulocyte colony-stimulating factors: finding the right indication. Curr Opin Oncol. 2007;19:299-307.

255. Maher DW, Lieschke GJ, Green M, Bishop J, Stuart-Harris R, Wolf M, Sheridan WP, Kefford RF, Cebon J, Olver I, McKendrick J, Toner G, Bradstock K, Lieschke M, Cruickshank S, Tomita DK, Hoffman EW, Fox RM, Morstyn G. Filgrastim in patients with chemotherapy-induced febrile neutropenia. A double-blind, placebo-controlled trial. Ann Intern Med. 1994;121:492-501.

256. Vellenga E, Uyl-de Groot CA, de Wit R, Keizer HJ, Löwenberg B, ten Haaft MA, de Witte TJ, Verhagen CA, Stoter GJ, Rutten FF, Mulder NH, Smid WM, de Vries EG. Randomized placebo-controlled trial of granulocyte-macrophage colony-stimulating factor in patients with chemotherapy-related febrile neutropenia. J Clin Oncol. 1996;14:619-27.

257. Garcia-Carbonero R, Mayordomo JI, Tornamira MV, López-Brea M, Rueda A, Guillem V, Arcediano A, Yubero A, Ribera F, Gómez C, Trés A, Pérez-Gracia JL, Lumbreras C, Hornedo J, CortésFunes H, Paz-Ares L. Granulocyte colony-stimulating factor in the treatment of high-risk febrile neutropenia: a multicenter randomized trial. J Natl Cancer Inst. 2001;93:31-8.

258. Clark OA, Lyman GH, Castro AA, Clark LG, Djulbegovic B. Colony-stimulating factors for chemotherapy-induced febrile neutropenia: a meta-analysis of randomized controlled trials. J Clin Oncol. 2005;23:4198-214. 